\title{
Dışarıda Yeme Kültürü ve Lokantalar: Rize Örneği ${ }^{1}$
}

\section{ihsan SAFi' ${ }^{2}$, Gülhan ATNUR ${ }^{3}$, Damlanur KÜÇÜKYILDIZ ${ }^{4}$}

\section{Öz}

İnsanların kimliği, ekonomik ve sosyo-kültürel durumu, yaşam şekli vb. birçok özelliğini onların beslenme alışkanlıkları sayesinde öğrenebiliriz. Işslevsel halkbilimi kuramında kültür aktarımının insanoğlunun fiziksel ve ruhsal birçok ihtiyacına cevap verecek şekilde düzenlendiği iddia edilir. Çalışmanın amacı değişim ve dönüşüm geçirmeye başlayan Rize'de yöre halkının dışarda yemek yeme alışkanlıklarıyla ilgili sosyo-kültürel sebepleri ortaya koymak, yemek yenilen lokanta/restoran gibi yerlerin turizm ve kültüre katkılarını, ayrıca lokantacılık mesleğinin Rizelilerin yaşamındaki yerini işlevsel teori bağlamında ele alıp tespit etmektir. Rize'deki dışarıda yemek yeme kültürünün lokanta ve onların biraz daha modern hali olan restoranlar bağlamında ele alındığı bu çalışmanın malzemesi ise halkbilimi saha araştırmalarında yaygın kullanılan gözlem ve görüşme teknikleri kullanılarak derlenmiştir.

Anahtar Kelimeler: İșlevsel halkbilimi kuramı, Rize, Yemek Kültürü, Dışarıda Yemek, Lokantalar, Restoranlar.

\section{The Culture of Eating Out and Eating-Houses: The Case of Rize}

\begin{abstract}
Eating habits reflect peoples' many features lime their identity, economic, and socio-cultural status, and lifestyle. In functional folklore theory, it is claimed that cultural transfer helps human beings in a way to meet their many physical and spiritual needs. This study aims to reveal the sociocultural reasons related to the eating habits of the local people in Rize, which has started to undergo change and transformation, to consider the contribution of places such as eating-houses/restaurants to the tourism
\end{abstract}

\footnotetext{
${ }^{1}$ Bu makale Damlanur KÜÇÜKYILDIZ’ın Recep Tayyip Erdoğan Üniversitesi Sosyal Bilimler Enstitüsü Türk Dili ve Edebiyatı Anabilim Dalında hazırlamakta olduğu doktora tezinden türetilmiştir.

2 Prof. Dr. İhsan SAFi, Recep Tayyip Erdoğan Üniversitesi Fen Edebiyat Fakültesi Türk Dili ve Edebiyatı Bölümü, ihsan.safi@erdogan.edu.tr, ORCID ID: 0000-0003-0659-2329.

3 Prof. Dr. Gülhan ATNUR, Atatürk Üniversitesi Edebiyat Fakültesi Türk Dili ve Edebiyatı Bölümü, gatnur@atauni.edu.tr, ORCID ID: 0000-0003-4755-7175.

${ }^{4}$ Arş. Gör. Damlanur KÜÇÜKYILDIZ, Recep Tayyip Erdoğan Üniversitesi, Fen Edebiyat Fakültesi Türk Dili ve Edebiyatı Bölümü, damlanur.kucukyildiz@hotmail.com, ORCID ID: 0000-0002-2205-1218.
} 
and culture, and to determine the importance of the eating-house profession for the life of people who live in Rize within the context of the functional theory. The material of this study, in which the culture of eating out in Rize is handled in the context of eating-houses and their slightly more modern versions as restaurants, was compiled using observation and interview techniques commonly used in folklore field research.

Keywords: Functional folklore theory, Rize, Food Culture, Eating Out, Eating-Houses, Restaurants.

\section{Extended Abstract}

With the changing lifestyles and regarding eating out as a social activity, eating out has become a need today. Therefore, eating-houses have become important places for people who are away from their homes or want to taste different flavours, who come from other countries or cities and want to try the traditional food of where they go.

Restaurants are places not only for eating but also for socializing. They have become places where friends come together and have a conversation while having a meal together, where events are organized since meeting at home is troublesome, where business meals or special day meals are eaten, and where meetings are held. Briefly, eating-houses offer the opportunity to save time, meet new people, to be with family / spouse / friends, provide entertainment, happiness, healing in the mood, and have many functions such as ease, economy and eliminating hunger.

Through observations and interviews, this study examines eating-houses and restaurants in Rize. Face-to-face interviews were done with the eatinghouse owners, the information obtained from the observations in the eating-houses and the examination of the menu cards were evaluated. Besides, conversations with the local people were held. Evaluations were made in the light of the information received from the source people and observations in the region. Thus, the culture of eating out of the region was examined through eating-houses. The study is limited to the eatinghouses in Rize, which have a long history and focus on local food.

Eating out culture is quite common in Rize. There are many reasons for this. However, increasing the economic income of the region, interest in different tastes, delicious tastes of the restaurant meals, being fond of the comfort, and working women are the most prominent reasons. Significant changes have occurred in the region in terms of eating out culture from past to present. Restaurants that appeal to people from almost every economic level today appealed to a limited audience for different reasons besides economic income in the past. Especially women's going to eatinghouses was not regarded as favorable due to religious or cultural reasons in the past. Today, it is seen that such situations are not in question, and women eat at eating-houses freely. It can be said that the eating-houses in the region have an important place in many social activities such as hosting guests from other cities, organizing visiting days, giving business meals, meeting the food needs required at funerals and weddings as well as meeting individuals' food needs. 
In this era when gastronomic tourism is in great demand, a related industrial area has been formed in Turkey as in the world. People participate in tourism with the purposes of getting to know different culinary cultures and seeing them on site, tasting different tastes and with the similar reasons. Local cuisines, which are an important part of Turkish cuisine, are important tools in terms of making the region a touristic attraction and reflecting the characteristics of the geography in which they are located. In the local restaurants, which are also important in this regard, foods such as muhlama and stuffed cabbage are made. These local tastes prepared in restaurants are offered to the attention of customers, especially those who are from other cities and want to taste the local tastes.

Besides, eating-houses with a historical background were introduced in the study. It was found that most of these places in the province and its districts have a tradition passing from generation to generation, and people of Rize run eating-houses in other cities as well. When the eatinghouses with a long history in Rize are generally examined, it is understood that many places are family businesses, running eating-houses is learned in the form of a master-apprentice relationship, and usually starts at a young age. Young people who learn the intricacies of the profession by working with their family elders outside school grow up in a tradition transferred from father to son and take over the job when the time comes. Historical restaurants introduced in the study are Hüsrev Restaurant, Huzur Restaurant, Liman Restaurant, Halil İbrahim Restaurant, Lale Restaurant and Durak Restaurant, respectively. Discussing the history, owners, customer profile, traditional structure, master-apprentice relationship, and dishes of these introduced restaurants is important for evaluating the eating-out culture and eating-houses of the region in terms of folk culture. 


\section{Giriş}

Beslenme temelde biyolojik bir eylemdir. İnsan metabolizmasının enerji ihtiyacının sağlanması için gerekli olan besinlerin temini, insanların tüketimi için uygun hale getirilmesi ve tüketim davranışları süreci, beslenmeyi salt biyolojik bir eylem olmaktan çıkararak kültürel bir olgu haline dönüştürmektedir (Beşirli, 2010: 159). Bu kültürel olgu, gerek ev içinde gerekse ev dışı alanda kendisine yaşam alanı bulmuştur. Yemek kültürünün oluştuğu ev dışı beslenme alanlarından birisi de lokantalardır.

Kâmûs-ı Türkî’de Şemseddin Sami, lokanta kelimesinin kökenini İtalyanca olarak gösterir ve kelimenin anlamını şu şekilde verir: Ücretle yemek yenilen yer; alafranga aşçı dükkânı; yabancıların ve yolcuların yatıp kalkmasına ve yemek yemelerine mahsus umumî hane ve daire, misafirhane, hotel (Şemseddin Sami, 2004: 1247, 1248). Türkçe Sözlük'te ise lokanta kelimesi, “1. Yemek pişirilip satılan yer, aşevi, restoran. 2. Hlk. Aşçı.” şeklinde tanımlanmıştır (Türkçe Sözlük, 2011: 1591).

Ev dışında yemek yenilen yerler geçmişte aşhane, aşevi, aşçı dükkânı gibi bazıları günümüzde de kullanılan isimlerle adlandırılmıştır. Selçuklu ve Osmanlı zamanında yemek pişirilen ve satılan aşçı dükkânları, tatlıcı dükkânları vardı. Fakat bunlar başlı başına bir yapı arz etmeyip hanlar ve kervansarayların içerisinde bulunmaktaydı. Daha sonra bu yapılar bağımsızlaşarak yaşamımıza lokantaların girmesini sağlamıştır. Sanayileşme ve kentleşme olgusuyla beraber bireylerin seyahat etme olanakları, evlerinden uzak kalma serbestliğine sahip olmaları, bunun sonucunda yakınlarla bir bağlantı kurabilme teminatının olmaması gibi durumlar dışarıda yemek yemenin ticari bir faaliyete dönüşmesine sebep olmuştur (Beardsworth-Keil, 2011: 175, 176). On dokuzuncu yüzyılın sonunda zenginleşen büyük esnaf ve gelişen tüccar sınıfı için büyük çarşı semtlerinde aşevi veya çarşı lokantası denilen ve ev yemeklerini daha uygun bir ortam ve hizmet anlayışıyla sunan, temizliğe önem veren yerler açılır (Gürsoy, 2013: 149). Ülkemizde Cumhuriyetle birlikte lokantacılık sektöründe önemli ilerlemeler görülmüş ve yeni yerler açılmıştır. 1980'lerden itibaren Türkiye'de serbest piyasa ekonomisinin yerleşmesi, pazar ekonomisinin genişlemesi, şehirlere yoğun göç akımı, kadınların iş hayatına kitlesel katılımı ve yerel, bölgesel, ulusal mutfakların keşfedilmesiyle birlikte (Onaran, 2016: 50; Sauner, 2008: 266; Kunduz ve Yirmibeşoğlu, 2019: 35) dışarıda yemenin yaygınlaşması söz konusudur. Fakat Türkiye'de lokanta kültürü özellikle İstanbul'da giderek gelişse de 80'lerin sonuna kadar lokanta ve restoranlar belli bir sayının üzerine çıkamaz (Kunduz ve Yirmibeşoğlu, 2019: 34). 80 öncesi dışarıda yemek yemek sadece ekonomik düzeyi düşük sınıflar için değil aynı zamanda orta sınıflar için de az tecrübe edilen bir olguydu. Restorana gitmek ancak arada bir yapılabilecek ve kutlama gibi sebeplere ihtiyaç duyacak bir konuydu. Türkiye'de restoranların çeșitlenmesi bir yandan her kesimden insanın dışarıda yemek yiyebilmesinin yolunu açarken bir yandan da ekonomik farklılıkların iyice belirginleşmesine, 
beğeni ve zevkin gittikçe kimliği tarif eden bir unsur olmasına yol açtı (Kunduz ve Yirmibeşoğlu, 2019: 38). Bugge ve Lavik, dışarıda yemek için lüks, zevk ve sosyalleşme gibi birçok sebep ve gereklilik olduğunu söyleyerek i̇sveç'te yapılan bir çalışmanın dışarıda yemek yemeyi çok boyutlu bir deneyim olarak analiz ettiğini, bu yüzden bir restorana gitmenin sadece yemeyle ilgili olmadığını belirtir. Bu bağlamda öğle yemeğinde restorana gitmek daha çok fizyolojik bir ihtiyaçken akşam yemeğinde restorana giden müşteriler için bunun sosyal boyutunun daha önemli olduğu örneği verilir (Bugge ve Lavik, 2010: 217).

Lokantalar, evinden uzakta olan veya farklı lezzetleri tatmak isteyen, başka ülkelerden veya şehirlerden gelen ve geldikleri yörenin lezzetlerini merak edip denemek isteyen insanlar için günümüzde büyük bir ihtiyaç haline gelmiştir. İnsanın doğal bir ihtiyacı olan beslenme, özellikle günümüzde büyük bir sektördür. Günümüzde yaşam şartlarının değişmesiyle ve bireylerin, ailelerin dışarıda yemeyi sosyal bir aktivite olarak görmesiyle dışarıda yemek yeme bir gereksinim haline dönüşmüştür. ${ }^{5}$ Lokantalar, içinde bulundukları şehirde yaşayan insanlar için de büyük bir öneme sahiptir. Günlük yaşam içerisinde evdeki yemeği beğenmeyen, yemek pişirmeye vakti olmayan veya yemek pişirmeyi bilmeyen, dışarıda yemeyi seven, yemek yapacak kimsesi olmayan, özel bir buluşması olan, özlediği bir tadı arayan, farklılık olmasını isteyen, dışarıda işi olup eve yetişemeyen birçok kişi, lokantaya gider. Lokantalar, sadece yemek yenilen yerler değildir, aynı zamanda sosyalleşme mekânlarıdır. Arkadaşların bir araya geldiği, birlikte yemek yerken muhabbete de ortak oldukları, kimi zaman evlerde buluşmanın zahmetli olmasından dolayı yapılacak eğlencelerin dışarıya taştığı, iş yemeklerinin, özel gün yemeklerinin yendiği, bazen toplantıların yapıldığı yerler olmuştur. ${ }^{6}$ Kısaca lokantalar, zaman tasarrufu, yeni insanlarla tanışma, aile/eş/dost/arkadaşlarla birlikte olma olanağı sunmakta, eğlence, mutluluk, ruh halinde iyileşme sağlamakta, kolaylık, ekonomiklik ve açlığı giderme gibi pek çok işlevi bünyesinde taşımaktadır.

\section{Araștırmanın Amacı, Kapsamı ve Yöntemi}

Rize'de yemek kültüründeki zenginliğin ve lokantacılığın tarihini çok eski dönemlere götürmek için yeterli kaynak yoktur. Seyyahlar, tarihi kayıtlar ve diğer eserler bu konuda ayrıntılı bilgi vermezler. Sahip olduğu kültürel yapı sebebiyle Rize'de dışarıda yeme konusunda köklü bir yemek kültürü oluşmasına rağmen konu hakkında yeterli çalışma yapılmamıştır.

\footnotetext{
${ }^{5}$ Bkz. (Akarçay ve Suğur, 2015: 5-7).

${ }^{6}$ https://www.hurriyet.com.tr/lezizz/galeri-gunlerde-ikram-ediliyordu-artik-restoranlara-da-tasindi-41371051/2 (Erişim Tarihi: 20.04.2020)

https://www.comlek.com.tr/hizmetler/is-toplantisi-yemek-organizasyonu (Erişim Tarihi: 20.04.2020).
} 
Özellikle Cumhuriyetten sonra il olması, Rize'nin kamu harcamalarından daha fazla pay almasını sağlamış ${ }^{7}$ çay üretimi şehrin ekonomik, sosyal ve kültürel hayatının da değişmesine yol açmıștır. ${ }^{8}$ Yörenin yemek kültürüyle gelişmeye ve zenginleşmeye başlayan lokantacılık da zamanla hem Rizeliler hem de Türkiye'nin ve hatta dünyanın dört bir yanından gelenlerle geleneksel yapısına kavuşmuştur.

Rize'de çok sayıda lokanta ve restoran mevcuttur. Çalışmanın kapsamı dikkate alındığında bunların hepsine yer verilmesi mümkün görünmemektedir. Bu sebeple çalışmada incelenen işletmeler yöresel lezzetlere yer verenler ve kuruluş tarihi eski olanlarla sınırlandırılmıştır.

Bu çalışmanın amacı değişim ve dönüşüm geçirmeye başlayan Rize'de yöre halkının dışarda yemek yeme alışkanlıklarıyla ilgili sosyo-kültürel sebepleri ortaya koymak, yemek yenilen yerlerin -lokanta/ restoran- turizm ve kültüre katkılarını tespit etmektir.

Rize'deki dışarıda yemek yeme kültürünün lokanta ve onların biraz daha modern hali olan restoranlar ${ }^{9}$ bağlamında ele alındığı bu çalışmanın malzemesi halkbilimi saha araştırmalarında yaygın kullanılan gözlem ve görüşme teknikleri kullanılarak derlenmiştir. Uzun yıllardır bu şehirde yaşıyor olmamız Rize'deki lokanta/restoranları ve müșterilerini doğal ortamlarında gözlemleme ve notlar almaya imkân sağlamıştır. Halkbilimi çalışmalarında doğal ortam gözlem için ideal şartları sağlamakta ve doğru tespitlerin yapılmasına olanak tanımaktadır (Ekici, 2007: 68, 69; Çobanoğlu, 2012: 83). Gözlemin denetlenmesinde en etkili yöntemlerden biri görüşmedir. Rize ilindeki dışarda yeme alışkanlıkları ile işletmelerin genel yapısı, işletmecileriyle yüz yüze görüşülerek tespit etme yoluna gidilmiştir. Derleme yoluyla elde edilen malzeme işlevsel halkbilimi kuramıyla ele alınmıştır.

İşlevsel halkbilimi kuramında kültür aktarımının insanoğlunun fiziksel ve ruhsal birçok ihtiyacına cevap verecek şekilde düzenlendiği iddia edilir. Bu ihtiyaçlar sonraki kuşaklara da aktarılır. Ortaya çıkacak yeni ihtiyaçlar insanların yeni emir ve koşullara zorlanması anlamına gelir (Malinowski, 1992: 66). Bronislav Malinowski'ye göre kültür insan elinin eseri olduğu gibi amaca ulaşmakta da önemli bir araçtır. Bu sebeple beslenme hem temel hem de kültürel bir ihtiyaçtır. Beslenme, örgütlü grup ve örgüt içinde önceden belirli bir alet aracılığıyla hazırlanan, sofra düzeninde sunulan, kurallar ve törelerle şekillenen bir yapıya sahiptir (Malinowski 1992: 108-109). Yani kültür, özel olduğu düşünülen bu

\footnotetext{
7 Ayrıntılı bilgi için bkz. (Bilici, 2018).

${ }^{8}$ Ayrıntılı bilgi için bkz. (Duman, 2005).

9 Çalıșmaya konu olan lokantalar daha çok esnaf grubuna hitap eden ve "esnaf lokantası" şeklinde ifade edilen, çalışanlarla müşterilerin samimi bir şekilde konuştuğu, yemeklerin görünür bir tezgâh üzerinde sergilendiği, menü kartları olmasına rağmen müşterilerin yemek tercihlerini bu tezgâhlardan görerek de yapabildiği yerlerdir. Restoranlar ise daha çok menü usulüyle çalışan işletmeler olarak düşünülebilir. Bazı "esnaf lokantası"sı sahipleri, iş yerini genişlettikten ve çalışan sayısını artırdıktan sonra restoran adını tercih etmektedirler (KK.5).
} 
ihtiyacı grup oluşturmak, yeni kuşaklara aktarmak ve kimlik kazandırmak için farklı bir forma büründürmüştür.

Çoğu zaman halkbilimcilerinin göz ardı ettiği işlev konusu, halk bilgisi yaratmalarının bir sosyal ilişkinin ürünü olduğunun ortaya konması gibi sonuçları beraberinde getirmesi açısından da oldukça önemlidir (Ekici, 2007: 124). Hangi seviyede olursa olsun bütün toplumlarda aynı sofrayı paylaşma olgusu vardır. Her toplumda ve herhangi bir toplumun herhangi bir bireyi ele alındığında yemek yeme işinin belli bir kurum içinde gerçekleştiği görülür. Burası bir ev, bir lokanta yahut bir öğrenci yurdu olabilir. Onun yeri sabit kalır. Yiyeceğin sağlanması veya hazırlanması için bir örgütü ve yemeğin tüketimini sağlayan imkânlar vardır (Çobanoğlu, 2012: 249). Beslenme olgusunun örgütlenmiş gruplar ve örgüt içinde gerçekleştiriliyor olması onun işlevsel halkbilimi kuramıla incelenmesi gerekliliğini doğurmuştur.

\section{Rize'de “Dışarıda Yeme” Kültürü}

2019 yılında Rize Lokantacılar Odasından kendilerine kayıtlı olan yöredeki lokantaların sayısını ve isimlerini içeren bir liste istenmiştir. Verilen belgede merkeze kayıtlı kasap, kafe (cafe) ve lokantalar karışık bulunmakta ve bunların sayısı 105 olarak gösterilmektedir. Lokanta, kafe (cafe), kasap gibi farklı işletmelerin bir arada verildiği bu listede kafe (cafe), kasap vb. yerler çıkarıldığında içerisinde çiğ köfte ve pide salonları da bulunan toplam 72 adet lokantanın yer aldığı söylenebilir. Rize Sanayi ve Ticaret Odasına bağlı "Diğger lokanta ve restoranların (içkili ve içkisiz) faaliyetleri (garson servisi sunanlar ile self servis sunanlar dâhil, imalatçıların ve al götür tesislerin faaliyetleri ile seyyar olanlar hariç)" grubu altında ise şehir merkezinde 18 lokanta yer almaktadır. ${ }^{10}$ Bunlar içerisinde pide, balık, fast food (çiğ köfte, lahmacun) ismiyle yer alanlar vardır. Verilen bu lokanta sayıları dışında kalan yeme-içme mekânları da oldukça fazladır. Bu lokantalar gözlemlendiğinde lokanta sayısının fazlalığına oranla doluluk açısından bir problem yaşanmadığı dikkat çekmektedir. Bu durum, Rize insanının dışarıda yeme alışkanlığının fazlalığını da gözler önüne serer niteliktedir. Görüşme yapılan kişiler, yörede dışarıda yeme oranının fazla olmasını, yemeğe düşkün olmakla açıklamakta, evde yemek olsa da lokantaları tercih ettiklerini belirtmektedirler. Yöre kültürüne hizmet etmiş ve yöreyle ilgili önemli çalışmaları bulunan kaynak kişilerden KK.1, lokantaların doluluğunu insanların parası olduğu

\footnotetext{
${ }^{10}$ Listede Bekiroğlu gibi bazı kapanmış olan lokantaların da yer alması lokantalarla ilgili net bir sayı vermemize engel olmaktadır. Bundan başka Ticaret Odasının sayfasında yer alan listedeki "Çay ocakları, kıraathaneler, kahvehaneler, kafeler (içecek ağırlıklı hizmet veren), meyve suyu salonları ve çay bahçelerinde içecek sunum faaliyeti”, “ Pastanelerin ve tatlıcıların (sütlü, şerbetli vb.) faaliyeti (garson servisi sunanlar ile self servis sunanlar dahil, imalatçıların ve al götür tesislerin faaliyetleri ile seyyar olanlar hariç)", "Dışarıya yemek sunan diğer işletmelerin faaliyetleri (spor, fabrika, işyeri, üniversite, vb. mensupları için tabldot servisi, vb. dahil, özel günlerde hizmet verenler hariç)", "Yiyecek ağırlıklı hizmet veren kafe ve kafeteryaların faaliyetleri", "Oturacak yeri olan fast-food (hamburger, sandviç, tost vb.) satış yerleri (büfeler dahil) tarafından sağlanan yemek hazırlama ve sunum faaliyetleri" gibi işletmeler verilen bu sayının dışında tutulmuştur. http://rizetso.org.tr/wpcontent/uploads/2020/01/17-meslek-grubu.pdf (Erişim Tarihi: 10.02.2020).
} 
için dışarıda yemesine bağlar. KK.1, eskiden sadece birkaç içkili (alkollü) lokantanın olduğunu, insanların buralara içki içmeye gittiğini, içkisiz lokantaların daha sonra yayılmaya başladığını, ayrıca para kazanmaya başlayan kişilerin lokantalarda yemek yemeye başladığını belirtmiştir. Eski bir fırıncı ve lokantacı olan KK.12 de KK.1'in söylediklerini doğrulamış, içkinin yasaklanmasıyla lokantalarda sadece yemek verilmeye başlandığını ifade etmiştir. Kaynak kişilerin ifadeleri, Rize'deki lokantaların ilk zamanlardaki müşteri profilini de açıklar niteliktedir.

Lokantada yemek yemek belli bir düzeyde maddi geliri de elinde bulundurmayı gerektirmektedir. 1950'lerden itibaren çay sektörünün gelişmesiyle Rize insanının refah seviyesini yükseltmiş; ekonomik açıdan rahatlayan bölge insanı, eğlenceye ve yeme-içmeye daha çok maddi imkân bulmuştur. Bu vesileyle iç mekân olarak evde beslenme alışkanlığı, farklılık, başka lezzetler tatma olanakları sunan, farklı sosyal sınıfları birleștiren bir dış mekân olan lokantalara talebi artırmıștır. Bu bağlamda Huzur Restaurant sahibi KK.5 de yapılan görüşmede çaydan sağlanan para sayesinde dışarıda yeme oranının fazla olduğuna dikkat çeker. Lokantaların her kesimden insana hitap etmesi hemen olmayıp uzun bir süreci kapsamaktadır. Bu süreç ailelerin ekonomik durumuna göre değişiklik göstermektedir. Lale Lokantası işletmecisi KK.17 de lokantaya gitmeyle ekonomik gelir arasında bağ kurarak "eski dönemlerde zenginlik yoktu ki dışarıda yemek olsun. Adam gelir, marketten peynirini kavurmasını alır, kenarda köşede yerdi. Yetmişten önce lokantaya herkes gidemezdi." der. Akgül Pide işletmecisi KK.16, 1996-97’lerde lokantada yemek yemenin lüks bir olay olduğunu söyler ve "Ben kuaförde çalışırken evden minci1 ${ }^{11}$ götürüp yerdim." diyerek bu yüzden geçmişte lokantada yediği yemeklerin tadını hâlâ unutamadığını dile getirir.

Özellikle yakın geçmişe kadar aileler, okul civarındaki esnaf lokantası tarzı bir yerle anlaşıp çocuklarını öğlen yemek yemeye göndermekteydi. Tabii bunu herkes değil maddi durumu iyi olan aileler yapabilmekteydi, çünkü dönemine göre bir öğrencinin lokantada yemek yemesi iktisadî durumla ilişkiliydi. Dursun Ali Sazkaya, anılarını anlattığı yazısında lokantaya gitme macerasının ve orada daha önce tatmadığı yemeklerle karşılaşmasının dedesi sayesinde olduğunu söyler ve olayı şu şekilde dile getirir:

“...Başkalarına öykünmesinler diye, sırasıyla her ay birimizi lokantaya götürür, elinden geldiğince yedirir, içirirdi. Kadayıf tatlısını, mercimek çorbasını hayatımda ilk defa lokantada onun sayesinde tatmıştım. Çorba meselesi garip gelebilir, ama Lazlarda çorba kültürü olmadığından çorbayı bilmezdik.

\footnotetext{
${ }^{11}$ 1. Çökelek, lor. 2. Ayran, ekşidiğinde ya da ekşimeden ateşte karıştırılarak kaynatılır. Ateşten alınarak soğumaya bırakılır ve suyunun süzülmesi için bir torbaya konulduktan sonra yüksekçe bir yere asılır. Böylece mincinin suyu süzülmüş olur ve yemek için hazır hale gelir. Eğer minci uzun süre saklanacaksa tuzlanmalıdır. Yörede kahvaltıların vazgeçilmezi olan minci, kesilmiş sütten de yapılmaktadır.
} 
Hala ne zaman bir mercimek çorbası içsem dedem düşer aklıma. Orta mektebe giderken, öğle yemeğini hep lokantada yemiştim. Bunu ona borçluyum. O dönemin iktisadi koşullarında bir öğrencinin lokantaya gitmesi ayrıcalıklı bir durum sayılırdı. Dedem rahmeti rahmana kavuştuktan sonra bu ayrıcalığımı da yitirmiştim. Ben de diğer yoksul arkadaşlarımla beraber adını Dereboyu Restoran koyduğumuz, ekseriyetle kuru ekmekten, nadiren de olsa helva ve peynirden oluşan öğle yemeğini Fırtına deresinin kenarında yemeye başladım." (Sazkaya, 2015: 35, 36).

$\mathrm{Bu}$ ifadeler o dönemde lokantaya gitmenin bir sosyal statü göstergesi olduğunu açıklar niteliktedir. Aslında bugün de vaziyette çok fazla değişme olmamıştır. İnsanlar bütçelerine göre lokantalara gitmekte veya lokanta tercihi yapmaktadırlar.

Rize'de dışarıda yemek yeme kültürü, bölge insanının sadece ekonomik gelirin artmasıyla ilişkili değildir. Sütlaç ustası ve yörenin tanınmış işletmelerinden olan Sütlaççı Mustafa'nın sahibi KK.15, Rize'de lokantada yeme oranının fazla olduğunu ve lokantanın üst katında veya yakınında oturan yöre insanının bile lokantada yemese dahi dışarıdan evine yemek siparişi verdiğini, rahatlarına düşkün olduklarını belirtir. Hüsrev Lokantası işletmecisi KK.4, Rize'nin yemeklerinin güzel ve lezzetli olmasından dolayı insanların da dışarıda yemeğe ilgi duyduklarını söyler. Kadınların sürekli çalışmak zorunda kalması, evdeki yemek çeşitliliğinin az olması da dışarıda yeme sebepleri arasında sayılabilir. Akgül Pide işletmecisi KK.16, dışarıda yeme kültürüyle ilgili: "Günümüzde herkes çalıştığı için evde kimse yemek yapamıyor, zamansızlıktan dolayı mecburen dışarıda yemek zorunda kalıyorlar." demektedir.

Recep Tayyip Erdoğan Üniversitesinin 2006 yılında kurulup yörede varlığını güçlendirmesiyle kentin öğrenci nüfusunda artış yaşanmış, bu durum da genç nüfusun yemek tercihlerini daha kolay gözlemleme olanağı sunmuştur. Yörede öğrencilerin lokantadan ziyade kafe veya fast food satan yerlerde yoğunlaştığı görülmektedir. Bunun sebepleri arasında lokantanın belli bir yaş grubu üzeri kişilerin gittiği yer olarak görülmesinin yanında pahalılığı da yer almaktadır. Genç kuşağın fast food tarzı beslenmesi yeni bir yemek kültürü oluşturmaktadır. Bu durum, toplumsal yapı değiştikçe yemek kültürünün de değiştiğini göstermektedir. Mesela Huzur Restaurant sahibi KK.5'e göre lokantada yemek yeme öğrencilerin bütçesini zorladığı için onlar fast foodu tercih etmektedirler. Akgül Pide işletmecisi KK.16 ise gençlerin yanında küçük çocukların da fast foodu çok severek tükettiklerini belirterek ailelerin çocuklarını: "Notların iyi olursa seni Burger’a götüreceğim.” şeklinde kandırdıklarını, buna yakın zamanda şahit olduğunu söyler. Söz konusu durumlar yaygın olmakla birlikte gençlerin geleneksel olanla ilişki kurarak bazı lezzetleri bu tarz esnaf lokantalarına giderek tatmak istedikleri de yapılan görüşme ve gözlemlerden anlaşılmaktadır. 
Dışarıda yeme kültürü açısından yaşanan değişimlerden birisi de toplumsal cinsiyet farklılığı ve rolleridir. Kadın, daha çok ev içi alan içerisinde konumlandırımışken erkek ise kamusal alanda yemek için daha uygun görülen grup olmuştur. Bu konu hakkında lokanta sahipleriyle yapılan görüşmeler göstermiştir ki geçmiş dönemlerde kadının lokantaya gitmesi kısıtlıyken bugün söz konusu durumda önemli değişmeler yaşanmıştır. Söz konusu durumla ilgili KK5, eskiden hanımını alıp da değişiklik olsun diye dışarıda yemeye gitme oranının çok az olduğunu ifade eder. Eski dönemlerde "bir bayan lokantaya gidip yemek yer mi?” düşüncesinin çok yaygın olduğunu, fakat bu düşüncenin günümüzde fazla kalmadığını belirtir. İşletme sahiplerinden KK.10, dışarıda yeme kültürünün özellikle son on senedir yaygınlaștığını ifade eder. KK.10, bazı lokantalarda aile salonlarının olduğunu, bu lokantaların garsonlarının "buyurun efendim, aile salonumuz vardır" diye seslendiklerini ve ailelerin bu tür salonları tercih ettiğini söyler. Halil ibrahim Lokantası işletmecilerinden KK.9 ise eskiden erkeğin olduğu yerde kadının, kadının olduğu yerde ise erkeğin oturmak istemediğini; ayrı bölmelerde insanların haremlik-selamlık oturduklarını ifade eder. Bugün ise lokantalar her çeşitten, yaştan, cinsiyetten insana kapı açan, eşit derecede hizmet sunan, kadın-erkek arasındaki mekân farkının hemen hemen hiç görülmediği önemli kurumlar haline gelmiştir. İşletme sahiplerinden KK.5 de yine eskiden kadınların lokantada yemek yemediklerini, 52 yıllık meslek hayatı boyunca onların dışarıda sosyalleşmelerine bu işletmeler sayesinde ortam hazırladıklarını, önceleri sadece turist kafilelerinin peşinde avukatların, iş adamlarının hanımlarının lokantada gelip yemek yediğini belirtmekte ve "benim annem lokantada yemek yememiştir hiç, o zamanın tarihinde kadın yemek yerse ayıp sayılırdı." demektedir. Bu anlatılar göstermiştir ki lokantalar, geçmiş dönemlerde dini, kültürel vb. nedenlerle kısıtlı bir kadın kitlesine hitap ederken artık toplumsal cinsiyet ayrımı gözetmeksizin parası olan pek çok kişinin uğrak yeri konumundadır. Erhan Akarçay'a göre eşlerin her ikisinin de yoğun çalışma temposuna sahip olduğu ailelerde ev içi alanda mutfağa dair toplumsal cinsiyet rolleri açısından sorun yaşanmakta, bu yüzden dışarıda yemek zamandan tasarruf etmeyi sağlamakta ve ev-içi rollerde yaşanan sorunları azaltmaktadır (Akarçay, 2016: 111). Akarçay'ın bu ifadesi kadının yalnız çalışma hayatıyla değil yeme ihtiyacıyla da kamusal alanda yer bulduğunun göstergesidir.

Dışarıda yeme kültürü açısından dikkat çeken bir diğer nokta ise günümüzde insanların başka şehirlerden memleketlerine döndüklerinde yahut özledikleri bir tadın hasretini duyduklarında lokantalara gelerek bu özlemlerini gidermeleridir. Bu durum, gelenekselle ilişki kurma/ nostaljiyi yakalama noktasında oldukça önemlidir. Nostaljiyi yakalama açısından lokanta işletmecilerinden KK.6, birçok müşterisinin "Istanbul'dan yeni geliyorum, terminalden taksi tutup buraya geldim. Yemeğinizi özledim, yiyip eve gideceğim” dediğini dile getirir. Rize'deki lokantacılar, günümüzde ve geçmiş yıllarda köyden gelip de lokantada yemek yemeyen kişi sayısının çok az olduğunu dile getirmektedirler (KK.5, KK.6, KK.9). Rize'de eski zamanlardan beri özellikle Cuma 
namazı için ilçeden, köylerden gelen halkın lokantalarda yemek yemesi bir gelenek olmuştur. Lokanta işletmecilerinden KK.9, eskiden haftada bir kez çarşıya inen insanların doya doya lokantada karnını doyurduğunu söyler (KK.9). Ayrıca emekli maaşını almak için ayda bir köyden inen insanların lokantada karnını doyurarak evlerine gittiğini belli bir yaşın üzerindeki birçok kişiden duymak mümkündür (KK.5, KK.12, KK.13).

Lokantaların en önemli işlevlerinden biri, bireylere sosyalleşme imkânı sunmasıdır. KK.10, müşterilerin kendisine “Rize'nin sosyalleşmesinde çok büyük katkı sağladın” dediklerini belirtmektedir. KK.6 ise eskiden akşamları dışarıda yeme alışkanlığının pek olmadığını, bunun son dönemlerde oldukça yaygınlaştığını dile getirir.

Rize'de lokantalar, dışarıdan gelen misafirleri ağırlamak, altın günleri düzenlemek, iş yemekleri vermek, cenazelerde veya düğünlerde yemek ihtiyacını dışarıdan temin etmek için de oldukça önemli yerlerdir. Kadınların uzun süren gün yemeklerini lokanta/restoranlarda yapması, evde yemek yapmanın mümkün olmayacağı cenaze gibi acılı bir günde dışarıdan yemek söylenmesi, eskiden özellikle köylerde yapılan düğünlerin şehre taşınmasıyla birlikte evdeki yükü azaltmak amacıyla yemeğin dışarıda verilmesi gibi önemli sosyal faaliyetlerde Rize'de lokantacılık sektörü büyük bir eksikliği gidermeye çalışmıştır. Geçmişte evde yapılan birçok etkinlik, kolaylık sağladığı gerekçesiyle lokantalarda yapılmaya başlamıştır.

İslam dininin gerekliliklerinden biri olan oruç ibadeti, bölgenin yaşantısına etki ederek mekânsal bir çerçevede belirli bir zaman için yeme-içme kültürünü sınırlandırmıştır. Rize'de birkaç lokanta hariç Ramazan'da iftar için açık mekân bulmak oldukça zordur. Rize'de lokantalar, özellikle Ramazan aylarında açık olanlar büyük bir canlılık taşımaktadır. Iftar saatlerinde dışarıda kalmış insanlar için "bir lokantaya girip orucumu açayım.” gibi bir düşünce pek mümkün olmamaktadır, çünkü önceden aranarak rezerve edilen bu yerlerde boş mekân bulma ihtimali çok düşüktür. Lokantaların pek çoğunun Ramazan ayı boyunca kapalı olması, açık olanların ise iftar saatine doğru işlevsellik kazanması, yöredeki yemek kültürünün dinî bir ritüelle de birleştiğini göstermektedir.

Lokantalar, kültürel etkileşimde bulunulan yerler olması açısından da oldukça önemlidir. Gün içerisinde pek çok olayın yaşandığı bu yerlerde birçok halk kültürü ürünü oluşmakta, mizahi durumlarla karşılaşılmaktadır. Yöredeki lokanta kültürüyle bağdaşan fıkralaşmış durumlara birçok örnek verilebilir. Bunlardan birkaçı şöyledir:

Iştahlı adamın birisi lokantaya oturmuş, ekmek yerken terlemiş. Bu durum, garsonun dikkatini çekmiş. Adam kurnaz, garsonu yanına çağırmış ve "oğlum bu ekmeği hep yemek zorunda mıyım?" demiş. Garson da "yok amca, istediğin kadar ye." deyince adam bunun üzerine: "Oğlum daha once desene, terden su oldum; zannettum buni hep ben yiceğum.” der (KK.7). Bir diğer anlatı ise 
şöyledir: Adamın birini lokantanın kapısından davet etmiş, buyur gel! demişler. Adam da "ne demek seve seve gelirim" demiş. Sonrasında adam yemeğini yiyip teşekkür ederim diyerek çıkıp giderken kendisine para vermeyecek misin? diye sormuşlar. O da "ne para verecem, siz beni davet ettiniz" şeklinde cevap vermiş (KK.6). Başka bir örnek vermek gerekirse: "Rize'de adamın biri lokantaya gider. Patron "buyurun beyefendi, hoş geldiniz." der. Müşteri, yerine oturup uzun bir süre bekler, siparişini alan olmaz. Bakar ki kendisine sıra gelmeyecek, kalkıp kasaya gider. Patron hesap almak için, "afiyet olsun, buyurun ne almıştınız?" deyince adam da "iki buyurun, bir hoş geldiniz" cevabını verir" (KK.8). Buna benzer birçok anlatının, komik ve yaşanmış olayın yer aldığı bu kültürde en önemli durum, evlerde yapılan eğlencelerin, muhabbetlerin, yaşanmışlıkların, şakaların yerini yeni sosyal ortamlar olan lokantaların almasıdır.

Yörede yemek yemenin arkadaş, eş, dost buluşmaları, özel davetler vb. hallerde zevk için yenilen, saatlerce süren seramonilerden ziyade bir karın doyurma ihtiyacı olarak da algılandığı söylenebilir. Örnek vermek gerekirse öğlen saatlerinde memurların, esnafın hızlı hızlı yemek yediği görülmektedir. İş arası yenilen bu yemekler, uzun konuşmaların, sohbetlerin yapıldığı bir ortamdan ziyade açlığın giderildiği, kısa muhabbetlerin olduğu ortamlardır. Bu durumu bölge insanının karakterine bağlayan KK.5, şunu söyler: "Yemek yemek için vakit olur, dinlenerek yemek yersin. Rize'de öyle bir şey yok. Bizim burada insanlar oturunca acele acele hemen yemek ister, hemen gelmesini ister. Biz biraz tez canlıyız." Bir diğer kaynak kişi KK.17 ise: "Bizim Rize insanının şöyle bir özelliği var; müşterinin önüne çorba gelir, hemen içine ekmek doğrar. Niye doğrar? Çünkü acelecidir, hemen çorbanın soğumasını ister. Rizeli masaya oturunca, yemeğin hemen masaya gitmesi gerekir. Eğer bu serilikte servisi yapamazsan müşteriyi kaçırırsın." der. KK.5'in ve KK.17'nin söylediği sözleri genellemek doğru olmasa da insanların hızlı yemek tükettiklerini ve yemek konusunda sabırsız olduklarını söylemek yanlış olmaz.

\section{Turizm ve Tanınırlık Açısından Yöre Lokantaları}

Gastronomi turizminin revaçta olduğu bu çağda, dünyada olduğu gibi Türkiye'de de bunun bir sektörel alanı oluşmuştur. İnsanlar, farklı mutfak kültürlerini tanıma ve yerinde görme, farklı lezzetleri tatma ve benzeri nedenlerle turizme katılmaktadırlar. Sırf yöresel yemek yemek için Rize’ye özellikle İzmir, Ankara, İstanbul gibi şehirlerden gruplar gelmekte, yöresel yemekleri tatma deneyimi yaşamaktadırlar. Türk mutfağının önemli bir parçası olan yöresel mutfaklar, bulundukları bölgeyi turistik cazibe merkezi haline getirmesi ve bulunduğu coğrafyanın özelliklerini yansıtması açısından önemli birer araçtır. Bu aracın en önemli taşıyıcıları da şüphesiz yöre lokantalarıdır. Böyle durumlarda işletmeler, daha geniş kapsamlı yöresel yemekleri yaparak müşteriler için sunuma hazırlamaktadır (KK.10). Turistik amaçlı yapılan gezilerin yanında şehir dışından gelen misafirlerine bölgenin yemeklerinden tattırmak isteyenler ise sipariş 
verdikleri yemeklerin yanında ortaya muhlama ${ }^{12}$ ve lahana sarmasını özellikle istemektedirler.

Lokantaların kendini tanıtması hem bölgesel turizm hem de ekonomi açısından önemlidir. Bunun için Rize'deki birçok lokanta sosyal medyada aktif olarak varlığı sürdürmektedir. Bir yöreye giden turistlerin gidilecek bölgenin hangi yemekleri meşhurdur, hangi lokantalarına gitmeden olmaz diye internet üzerinden ön hazırlık olarak araştırma yaptıkları herkes tarafından bilinen bir durumdur. Lale Lokantası işletmecisi KK.17, lokantaya gelen müşterilerine lokantadan nasıl haberdar olduklarını sorduğunda aldığı cevabın: "Internete girip bakıyorum, TripAdvisor'da size şu kadar puan vermişler, şu kadar memnuniyet var. Ona göre seçip geliyorum." olduğunu söyler. Yemek, aynı zamanda ucuz ve ulaşılabilir olmasıyla tercih edilen bir turizm aktivitesidir. Bambaşka bir şehirden sadece yörenin meşhur bir yemeğini tatmaya gelen veya sadece bir lokantanın güzel yemek yapmasından dolayı kilometrelerce yol yapanların sayısı azımsanmayacak kadar fazladır. Lokanta işletmecisi KK.2, insanların Rize'ye geldiğinde gereksinim duyacakları şeyi: “Buraya insan niye gelir? Elbise almazsın, marketten bir şey alırsın, lokantada yemek yersin.” şeklinde ifade ederek yemeğin başka bir şehre gidildiğinde gerekli görülen en önemli ihtiyaç ve merakı giderme aracı olduğuna vurgu yapar.

\section{Lokantaların İç Mekân Tasarımı ve Geleneksel Unsurları}

Yaşanan teknolojik gelişmelerle birlikte lokantaların iç mekân tasarımlarında bazı değişiklikler yapılmıştır. Bu gelişmeler, evlerdeki mutfak yapısını, malzemesini, kullanılan araç-gereçleri değiştirdiği gibi lokantaların mutfağında ve masa dizaynında da değişikliklere yol açmıştır. Geçmişte masaların üzerinde ibrikler ve krom bardaklar varken bugün cam sürahi ve cam bardaklar kullanılmaya başlamıştır (KK.12). Zamanında odun ateşinde taş fırınlarda pişen, pişirmede bakır tencerelerin kullanıldığı yemekler günümüzdeki teknolojik gelişmelerin etkisiyle, doğal gazlı, tüplü ocaklarda, bakır yerine krom tencereler kullanılarak hazırlanmaktadır. Fakat bazı lokantalarda yemeklerin lezzetini koruması için odun ateşinde ve bakır tencerelerde pişirilmesi geleneği eski dönemlerden beri devam ettirilmektedir. Bu durumdaki mekânların geleneğe vurgu yaparak ön plana çıkmaya çalıştıkları, bu geleneksellik çabasıyla başkalarından farklı olduklarını göstermek istedikleri de gözlemlenmiştir. Mekânı geniş olan bu lokantalarda önce tencere yemekleri tezgâhı yer almaktadır. Ortada kebaplar ve etler için ızgaralar kurulmuştur, diğer yanda ise pideler için fırınlar yakılmaktadır.

Yöre lokantalarının bazılarında başka şehirlerde de rastlanan şu unsurlar yer almaktadır: Kapıdan içeri girilirken "buyurun efendim, hoş geldiniz"

\footnotetext{
${ }_{12}$ Mısır unu, muhlamalık peynir ve tereyağından yapılan yöresel yemek. (Bu yemeğin başkaları tarafından mıhlama şeklinde ifade edilmesini yöre halkı eleştirmektedir.)
} 
denilmesi, masalarda sürahilerle suların bulunması, ödeme kasalarının yanında garsonlar için bahşiş kutularının yer alması, yemekten sonra ağızda hoş bir koku oluşmasını isteyenler için karanfil kutularının olması, bazı lokantalarda ise özellikle "garsonlara bahşiş vermeyiniz", "ödemeleri kasaya yapınız" yazılarının duvara asılması, lokantadan çıkarken "afiyet olsun, yine bekleriz." denilmesi ve müşterilere kolonya ikram edilmesi gibi...

\section{Farklı Deneyimler/ Yöresel Lezzetler}

Yemeklerde Rize halkı eti çok sevdiği için dışarıda para verdikleri yemeğin de daha çok et ağırlıklı olduğu görülür. Başka şehirlere oranla sulu yemek yapan lokantalar da şehirde fazlaca kendisine yer bulmaktadır. Bu durum şehrin yeme kültüründe büyük bir etkiye sahiptir ve koalisyon tabirinin ortaya çıkmasına yol açmıştır. Eski lokantacıların dört-beş çeşit sulu yemeği aynı tabakta buluşturmasından adını alan koalisyon, her kesimden insana, özellikle de esnaf ve memurlara hitap etmektedir. Evdeki sulu yemeği dışarıda yeme olanağı sunan böyle lokantalarda, öğle ve akşam saatlerinde büyük yoğunluklar yaşanmaktadır. Yörede karışık yemek tercihi ve sulu yemek çeşidinin bu kadar yaygın olmasıyla ilgili şu rivayetlere rastlanmaktadır: Eski aşçılardan Yakup Usta'nın her lokantada bir aşçısı vardır ve Rize'de karışık yemeğin başlamasına vesile olan aşçıbaşı bu kişidir (KK.7). Karışık yemek tüketiminin yörede fazla olması ise lokantaya gelen kişilerin sadece bir yemeğin değil de her çeşit yemeğin tadına bakmayı istemelerinden kaynaklı olduğu düşünülür (KK.17).

Lokantalarda yer alan dikkat çekici bir durum da pilav üstü kadayıf veya diğer bir ifadeyle pilav üstü tatlı geleneğidir. Tatlıyı seven yöre insanı, bunu bir de pilavla denemiş olmayı istemiş olsa gerek ki eski lokantaların hemen hepsinde bu tat bilinmektedir. Rize'deki eski düğünlerde de pilav üstü tatlı yenildiği bilinmektedir. Bunun bir yansımasını da lokantalarda pilav üstü kadayıf şeklinde görmekteyiz. Dışarıdan gelen insanların yadırgadıkları bu tadı, yörede de herkes benimsememiştir. Fakat talep eden de bir haylidir. Eğer pilav üstü kadayıf ve yanında kuru fasulye istenirse pilavın üstüne kuru fasulye, onun da üstüne kadayıf konulduğu ilginç durumlarla karşılaşmak mümkündür. Buna benzer bir diğer uygulama içinse turbo veya bomba terimi kullanılmaktadır. Turboda sütlacın üstüne kadayıf yahut nadiren baklava konulmakta ve böyle servis edilmektedir. Oldukça enerji veren bu tatlı, Karadeniz insanının akla gelmeyen tatları birleştiren özelliğinin bir yansımasının eseridir denilebilir. Yörede lokantaların hemen hepsinde sütlaç, vazgeçilmez tatlılar arasında birinci sırada yer almaktadır. Bunun dışında kabak tatlısı da birçok lokantanın menüsünde kendine yer bulmayı başarmıştır. Baklava ve kadayıf da menülerde yer alan diğer tatlılar arasındadır.

Ana yemeğin yanında meze ikramı geleneği, lokantalarda yaygın değildir, restoranlarda da özellikle son yıllarda rastlanmaktadır. Restoranların bazılarında 
yöre ekmeği koleti ${ }^{13}$, mısır ekmeği ile fasulye turşusu, tavalisi ${ }^{14}$ gibi yöreye özel lezzetler yemek öncesinde masaları süslemektedir. Mısır ekmeği özellikle balık lokantalarının en önemli mezesi durumundadır. Sipariş verilen balığın öncesinde masalarda mısır ekmeği ve turşu tavalisi ${ }^{15}$ yer almakta, sonrasında balık servis edilmektedir.

Yöre lokantalarında zamanla eskiden tadılmayan yemekler de yer almaya başlamış, menüler gittikçe çeşitlenmiştir. Yöre insanının farklı tatlarla karşılaşması, insanların hayatına daha önce tadılmayan lezzetlerin girmesi, KK.6'nın yaptığı şu yorumla daha iyi kavranır: “Çocukluğumda hatırlıyorum, okul döneminde şehre giderdim. Dönerciler vardı, bir de sulu yemek yapılırdı. İskender vs. olmazdı çocukluğumuzda. Bunlar daha sonra şehrin yemek kültürüne eklendi." Lokanta işletmecilerinden KK.14 ise Numune Lokantasının sahibi Ekrem Çemberci'nin o zaman Rize'de ilk döneri yapan kişi olduğunu belirtir.

\section{Lokantacı Rizeliler}

Lokantacılık sektörü, yöre insanı için gelenekselleşmiş bir iş sahası da oluşturmaktadır. Rizeliler sadece kendi şehirlerinde değil, başka şehirlerde de gidip lokantacılıkla uğraşmış ve işlettikleri lokantaların adlarını duyurmayı başarmışlardır. İstanbul'un esnaf lokantalarından Fasuli Lokantasının sahibi Mehmet Akif Köse, Rize'nin Çayeli ilçesi Aşıklar köyündendir, bu lokantanın birçok şubesi vardır (Gökyıldız, 2009: 80; Milor, 2014: 37). Rize'nin Çayeli ilçesinden sonra İstanbul, Ankara gibi şehirlerde de şubesi olan Hüsrev Lokantası, İstanbul'daki Refik Restaurant (Erkara, 2010: 78, 170) gibi daha adını bilmediğimiz birçok lokantanın Rizeliler tarafından işletildiği belirtilmektedir. Uğur Biryol, Fethi Yücel'in anlattıklarından hareketle Hemşinlilerin sadece pastacılıkta değil lokantacılık ve otelcilikte de ihtisaslaştığını, hatta bu branşların çoğu zaman iç içe geçtiğini söyler (Biryol, 2015: 147). Bölgede geçmişteki iş olanaklarının kısıtıılığından dolayı gurbete çıkan Rizeliler, başka şehirlerde lokantacılığı öğrenerek kendi memleketlerine dönmüş ve burada mesleği devam ettirmeye çalışmışlardır. Tabii yöredeki bütün lokantacılar için bunu söylemek mümkün olmasa da görüşme yapılan kişilerin kendisi veya ailelerinden birilerinin çoğunlukla mesleği başka şehirlerde öğrendiği anlaşılmaktadır.

Halkın hafızasında Rize'nin en eski lokantalarının hangileri olduğu tam olarak bulunmasa da Kanaat Lokantası, Kristal Lokantası, Numune Lokantası, Şehir Lokantası (KK.7, KK.6) gibi isimler yer almaktadır. KK.6, kendisinin çocukluk zamanlarına denk gelen 1986'lı yıllarda Akarsu Pide ve Kristal Lokantasının var olduğunu, burada yemek yediğini söyler. İlk ustalar arasında ise İshak Usta, Kadir Usta, ilyas Usta, Reşit Usta, Yakup Usta (Karali) gibi isimler sayılır (KK.7, KK.5).

\footnotetext{
13 Yuvarlak şekilli, küçük ve kabarık ekmek, pide.

14 Tavali kelimesi yörede kavrularak yapılan yemeklerin geneli için söylenir.

${ }^{15}$ Fasulye turşusunun kaynatılarak suyu sıkıldıktan sonra yağ ve soğanla tavada kavrulmasıyla yapılan yemek.
} 


\section{Yöresel Yemek Mekânları}

Rize'de geleneksel lokantalarla birlikte sektörel anlamda yöresel yemek yapan ve kültürel değerlere sahip lokantaların varlığı, şehrin yemek kültürünü tanıtmak açısından büyük bir role sahiptir. Evvel Zaman ve Dağmaran bunlar arasındadır. Evvel Zaman Yöresel Yemek ve Kültür Evi'nde karalahana sarması, muhlama, hamsili pilav, vurma lahana ${ }^{16}$, pepeçura ${ }^{17}$ gibi yöresel yemekler menülerde yer almakta, Rize'de yaşayan veya dışarıdan gelen müşteriler buraya geldiklerinde bu tatları deneme şansına sahip olmaktadırlar. Ayrıca mekânın iç dekoru da işletme sahipleri tarafından yöre kültürünü yansıtıcı şekilde dizayn edilmiştir. İşletmedeki yemeklerin sunumu ise bakır kaplarda yapılmaktadır. İsletme, farklı televizyon programlarında da kendisine yer bulmuş, bu programlarda çeşitli yöresel lezzetlerin yapımına yer verilmiştir.

İşletmeci KK.11, 1996'dan bu yana bu işi yaptıklarını söyleyerek Evvel Zaman'da haftada üç gün müzik yapıldığını da sözlerine ekler. Evvel Zaman'da başka yerlerde rastlanmayacak "Rize harman çorbası" ve "haymaana" isimli iki farklı lezzete de yer verilmektedir. Bu tatların Rize'de başka hiçbir işletmede yapılmadığını belirten KK.11, bunların yapılış macerasını da anlatır. KK.11, barbun fasulyesi ve yarma mısırla yapılan harman çorbası için eskiden yörede harman zamanı, sonbaharda bu çorbayı herkesin yaptığını, fakat kendilerinin çorbanın içine çarliston biberi ekleyerek tadını biraz değiştirdiklerini dile getirir.

KK.11, "haymaana” yemeğinin ise eși tarafından kıtlık zamanlarında ortaya çıkarıldığını şöyle anlatır: “Önceden biliyorsunuz, hayvancılık vardı. Mısır ekmeği, minci, yağ falan muhakkak her evde vardı. Biz bunu kıtlığa uyarladık. Bir yerden görmedik. Bir sahana tereyağı koyuyoruz, tereyağının üstüne bir günlük bayatlamış mısır ekmeğini ufatarak döküyoruz, minci ilave ediyoruz. Çok kuru olmaması için bir miktar da su ekliyoruz. İçine pul biber ekleyip pişmesine yakın yumurta kırıyoruz. Yumurtayı sahanda karıştırarak servise hazır hale getiriyoruz."

Yöresel lezzetleri bulabileceğimiz bir başka yer olan Dağmaran Restaurant ise hem şehirdeki hem de Rize'ye başka illerden ve ülkelerden gelmiş kişilerin en önemli uğrak yerlerinden biridir. Bunun en önemli sebeplerinden biri restoranın Rize'ye tepeden bakan bir konumda olmasıdır. Manzarasının güzelliği, seyir tepesi niteliğinde hem denizi hem de dağlarıyla birlikte geniş bir perspektifi gözler önüne sermesi, şehirden biraz da olsa uzaklaşmak isteyenlerin çok fazla ulaşım sıkıntısı çekmeden gidebilecekleri mesafede yer alması burayı diğer yerlerden ayrı kılan özelliklerdendir. Büyük bir işletme olan restoranın bir kısmının iç mekân dekoru ise tamamen yöresel eşyalar üzerinden tasarlanmıştır.

\footnotetext{
${ }^{16}$ Ana malzemesi karalahana, fasulye, mısır kırığı ve iç yağı olan blender ya da kepçe yardımıyla ezilerek yapılan yemek. (Ezme lahana, lahana ezmesi gibi farklı isimleri de vardır.)

${ }^{17}$ Yörede yetiştirilen kokulu siyah üzümlerden yapılan muhallebi kıvamındaki tatlı.
} 
Yöresel çoraptan, mutfak araçlarına kadar pek çok eşya restoranın duvarlarını süslemektedir.

2004'te küçük bir kulübeyle yemek yapımına başlayan işletme sahipleri, bugün çok sayıda insanı ağırlayacak olanağa sahip duruma gelmişlerdir. Onların küçük bir yerden büyük bir işletme haline gelmelerini işletme sahiplerinden KK.10, şu şekilde anlatır: "Kendimize bir çardak yaparken o zaman popüler kültür nargileydi, dört, beş tane nargile alalım dedik. Zaten 25 metrekare bir kulübemiz vardı. Çaylık aralarında bahçelerde korunmak için yapılan derme çatma tek gözlü kulübelere maran denir. Öyle 24 metre karelik maran yapmıştık. Çay ocağı, nargile kafe derken "acıkıyoruz, ne yapalım" dediler. Muhlama yapalım dedik. Sonra et türü de bir şey olsun dediler. Biz kendi aramızda buraya geldiğimizde bonfile alırdık, öyle dedik ki bunu koyalım. İsmine de maran kavurma diyelim dedik. Öyle oynarken baktık ki 15 yılın üstüne 25 metrekareden iki dönümlük bir tesise dönüştü. Sonra Rize'de ilk kahvaltıyı verdik. İnsanlar ilk defa ailesiyle birlikte kahvaltı yapmaya buraya geldi. Serpme kahvaltı verdik. Üst tarafı da yapınca hafta sonları da açık büfe kahvaltı vermeye başladık. Böyle başladık işe."

Aile işletmesi olan restoran sahiplerinin aileden gelen bir lokantacılık geçmişleri de bulunmaktadır. Dayılarının çok eski lokantacılardan olduğunu söyleyen KK.10, aileden gelen bir damak zevklerinin olduğunu, işletmenin tamamen ailenin üyeleri tarafından yürütüldüğünü, yemekleri kendilerinin yaptıklarını belirtir. Restoranda muhlama, sarma, fasulye tavalisi, pepeçura gibi yöresel yemekler yapılmaktadır. Dışarıdan turlarla gelen müşteriler olduğunda bu yöresel yemek sayılarında bir çeşitlemeye gidilir. En çok tercih edilen yemekleri arasında muhlama ve sac kavurmanın bulunduğu işletme, maran böreği ve maran kavurma gibi yeni tatları da Rize'ye kazandırmıştır (KK. 10).

Bağımsız Tüketici Değerlendirmeleri tarafından 2017'nin en iyi yöresel mutfak, 2018 ve 2019-2020'nin en iyi kahvaltı ödülünü alan işletme, Turgay Başyayla île Lezzet Yolculuğu, ${ }^{18}$ Mehmet Yaşin'in sunduğu Yol Üstü Lezzet Durakları, ${ }^{19}$ Ezgi Sertel ile Lezzet Haritası ${ }^{20}$ gibi birçok programda, aynı zamanda haberlerde vs. kendisine yer bulmuş, geniş çevrelere kendisini tanıtmayı başarmıştır.

Evvel Zaman, Dağmaran gibi yöresel yemeklere ağırlık veren, farklı tatları Türk mutfağına kazandırmaya çalışan restoranların yanında tarihi oldukça eskilere giden esnaf lokantalarının yörede fazlaca tercih edildiği bilinmektedir. Bu esnaf lokantalarındaki geleneksel ahşap masalar, tezgâhların üzerindeki sulu yemek çeşitleri ve çalışanların müşterilerle yaptıkları samimi konuşmalar, ilk göze çarpan unsurlardır.

\footnotetext{
${ }^{18}$ https://www.youtube.com/watch?v=DsdVYHxRSps (Erișim Tarihi: 20.02.2020).

${ }^{19}$ https://www.youtube.com/watch?v=jtlOqpjBvYY (Erişim Tarihi: 20.02.2020).

${ }^{20}$ https://www.youtube.com/watch?v=tYdYOC7EQeo (Erişim Tarihi: 20.02.2020).
} 


\section{Tarihi Lokantalar}

Insanların ne yediği gibi nerede yediği de önemlidir. Tarihi lokantalar başlığı altında verilen bu kısım, yörenin lokanta kültürünü, usta-çırak ilişkisini, lokanta işletmecilerinin bu sektöre olan katkılarını anlamak ve lokantaların öne çıkan yemek menülerini bilerek yörenin yemek kültürünü tespit etmek açısından oldukça önemlidir. Ayrıca bu kısım, lokantacıların iş anlayışlarının nasıl olduğunu, hammaddelerini nerelerden aldıklarını, lokantaların geleneksel yapıya nasıl kavuştuklarını anlayabilmek vb. birçok açıdan da oldukça önemlidir. Bunun yanında verilen bilgilerle Rize insanının lokantacılık geçmişi kavranacağı gibi bir nevi tarihi kalııılık sağlama ve işletmelerin gelecek kuşaklara aktarımına da imkân tanınacaktır.

Tarihi lokantalar başlğı altında ele aldığımız yerler hakkında bilgi verilirken bunların eskiden yeniye kuruluş tarihi esas alınmış ve sıralama buna göre yapılmıştır. Hakkında bilgi verilen bütün lokantaların işletme sahipleriyle birebir görüşmeler yapılmış ve yapılan görüşmeler, işletme sahiplerinin onayları doğrultusunda ses kayıt cihazına kaydedilmiştir. İşletmelerin tarihçesi ve bunlar hakkında verilen bilgilerin neredeyse tamamı, işletme sahiplerinin anlattıklarına dayanmaktadır. Bunun yanında lokantalar hakkında bilgi veren gazeteler, haberler, çeşitli web siteleri ve gözlemlerden de bu kısmı yazarken yararlanılmıştır.

\section{Hüsrev Lokantası/1958}

Hüsrev Lokantası, Rize'nin Çayeli ilçesinde Büyüktaşhane Mahallesi'nde yer almaktadır. Lokanta işletmecisi Fahri Hüsrev tarafından kurulan yeri günümüzde oğlu Selahattin Hüsrev işletmektedir. Lokanta hakkında bilgi aldığımız kişi Fahri Hüsrev'in oğlu Selahattin Hüsrev'dir.

Hüsrev Lokantasının tarihi çok eskilere dayanmaktadır. Abdullah Hüsrev, 1928 yılında Çayeli'nde bir bakkal dükkânı açar. Oğlu Fahri Hüsrev, bu dükkânın yarısını bölerek Temiz Süt Evi adını verir ve müșterilerine omlet ile süt servisi yapar. Temiz Süt Evi'nde işler iyi gidince menüye köfte de eklenmiş, Çayeli halkı bu hizmetten memnun kalmış olmalı ki Hüsrev Lokantasının temelleri burada atılmaya başlamış ve günümüze kadar varlığını sürdürmüştür. 1961 yılında yeni Belediye Sarayı'nın altındaki dükkâna taşınılmış ve Fahri Hüsrev burayı 1962'de Hüsrev Lokantası olarak hizmete sunmuştur. Adını sahibinin soyadından alan Hüsrev Lokantası açılınca fasulye, pilav, çorba, sütlaç, kadayıf yapımına başlanmış, fasulyeye ağılık verilmiştir. Fahri Hüsrev'den sonra lokantayı üç kardeş devralmıştır. Ankara ve İstanbul'da şubesi olan lokantayı Çayeli'nde Selahattin Hüsrev işletmektedir.

Lokantanın yemek menüsünde fasulye, pilav, köfte ve tavuk ızgara bulunmaktadır. Çayeli Ticaret Odasıyla birlikte kuru fasulyenin tescillenmesi 
sağlanmış ve lokantaların hizmete devam etmesiyle birlikte kuru fasulye yörenin lezzetleri arasında yerini almıştır. Fasulye özellikle Erzurum'un İspir ilçesinden, ihtiyaç halinde ise Erzurum/Hınıs ile Gümüşhane/Kelkit'ten temin edilmektedir. Tereyağı olarak ise Trabzon tereyağı kullanılmaktadır. Kendilerini özellikle fasulyeci olarak tanımlayan Hüsrev Lokantası sahibi Selahattin Hüsrev, kuru fasulyeyi nasıl yaptıklarına dair birkaç şey söyleme dışında ayrıntı vermemektedir: "Akşamdan suya koyuyoruz, suda 10 saat kalıyor. O suyu döküyoruz. Sonra fasulyeleri suya koyup kaynatıyoruz. Köpük veriyor, köpüğü alıyoruz. Et tereyağı, soğanı kavurup salçasını, suyunu ve tuzunu katıyoruz. Son olarak kaynatıp fırına atıyoruz, fırında pişiyor.” (KK.4). Artun Ünsal, Benim Lokantalarım isimli kitabında Trabzon'dan öteye "Hüsrev'in kuru fasulyesini yediniz mi?" sorusuyla sıklıkla karşılaşıldığını, lokantanın ününün Karadeniz’i bile aştığını söyler (Ünsal, 1996: 326). Aralarında önemli gurmeler, akademisyenler, yemek yazarları ve şeflerin bulunduğu 100 kișilik gastronomi heyeti, Türkiye'nin en lezzetli 100 yemeğini değerlendirmiş, Hüsrev Lokantasının kuru fasulyesi üçüncü sırada yer almıştır. Lokantayla ilgili Dilistan Shipman tarafından yapılan yorumda: Gösterişten uzak olan Hüsrev Lokantası, kapısından içeri girdiğiniz andan itibaren, sizi muhteşem bir yemek kokusuyla etkisi altına alıyor. Dev kazanlarda pişen kuru fasulye, pilav, turşu kavurması ve yoğurt! Bir akademisyen olarak size şunu söyleyebilirim: Başka söze gerek yok!" denilir (İzci, 2018).

Ustaları kendisi yetiştiren Selahattin Hüsrev, burada yetişen kişilerin çoğunun daha sonra ayrılarak kendilerine yer açtığını belirtir. Şu anki binayı kendilerinin yaptırdığını ifade eden Hüsrev, ellerinden geldiğince mesleği devam ettirmeye çalışacaklarını söyler. Rize'de iş olmadığı için eskilerin mecbur kalıp gurbete gittiğini ve başka şehirlerde lokantacılık öğrenip gelerek mesleği burada devam ettirdiklerini dile getiren Hüsrev, yemekleri kalaylı tencerede fırında pişirdiklerini, tatlı olarak eskiden revani, sonrasında sütlaç ve kadayıf yaptıklarını ifade eder ve sütlacı 1962'den beri yaptıklarını vurgular (KK. 4).

Temizlik ve lezzeti oldukça önemseyen işletmenin duvarlarını Cumhurbaşkanı'ndan sanatçısına kadar pek çok ünlünün lokantada çektirdiği fotoğraflar süslemiştir. Bunlar içerisinde cumhurbaşkanlarından Kenan Evren, Cevdet Sunay, Süleyman Demirel, Turgut Özal, Recep Tayyip Erdoğan ile yerli ve yabancı önemli kişilerin fotoğraflarını görmek mümkündür. Duvarlara fotoğraf yapıştırmanın 1983'te Turgut Özal'la babasının zamanında başladığını söyleyen Selahattin Hüsrev, bu geleneğin devam ettiğini, bugün lokantanın duvarlarının her tarafında fotoğrafların bulunduğunu belirtir (KK.4). Yani lokanta kendini tanıtmakta ve geleceğe taşımakta kültürel bellekten faydalanma yoluna gitmektedir.

Lokantayla ilgili bir diğer ayrıntı ise buraya gelen ünlülerin, önemli kişilerin mekânla ilgili deftere yazdıkları kısa yazılardır. Selahattin Hüsrev, bir defterlerinin daha olduğunu, o defterdeki yazıların daha eski olduğunu söyler. Hüsrev Turistik Tesisleri Şeref Defterinde Turgut Özal, Gani Müjde, Cüneyt Arkın, Uğur Dündar, 
Kazım Koyuncu gibi birçok ünlü ve siyasetçinin yazıları bulunmaktadır. Mekâna gelen kişiler, yazılarında tattıkları yemeklerin lezzetini, kuru fasulyenin methini, mekânın temizliğini, çalışanların güler yüzlülüğünü övmüşlerdir. Bu yönüyle hatıra defteri lokantanın tarihi geçmişini kanıtlayıcı ve güçlendirici bir role sahiptir. Diğer yandan ise bu durum, işverenlerin lokantaya gelen önemli kişilerin yazdığı yazılar, çekildikleri fotoğraflarla övünmelerini sağlamaktadır.

Lokantanın adını televizyonda da duyurduğu, Barış Manço'nun 1988 yılında Rize'ye geldiğinde Hüsrev Lokantası sahibi Fahri Hüsrev'le yaptığı görüşmeden anlaşılmaktadır. Videoda Fahri Hüsrev, fazla çeşit yemek yapınca kalitenin bozulduğunu, lokantada mercimek çorba, ızgara köfte, kuru fasulye, piyaz, ayran, fırında sütlaç, kadayıf ve revani yaptıklarını söyleyerek başarının sırrını "işinin başında olmak" ${ }^{21}$ şeklinde tanımlar.

\section{Huzur Restaurant/ 1966}

Rize/ Merkez/Cumhuriyet Caddesi'nde yer alan Huzur Restaurantla ilgili lokantanın işletmecisi İbrahim Tornacı'yla görüşme yapılmıştır.

Huzur Restaurant, 1966'da Rize/Merkez doğumlu ibrahim Tornacı tarafından kurulmuştur. Tornacı, çıraklığa pastacılıktan başlayarak bazı yerlerde dükkân açmıştır. 10 yaşında pastacılığa başlayıp 15 yaşında kendi işini kurmuş olan ibrahim Tornacı, 52 yıldır iş hayatında olduğunu belirtir. 1954 yılında İstanbul'a giderek Beyoğlu'ndaki Piknik Lokantasında 6 ay kalfa olarak çalışmış, daha sonra yaşadığı tecrübeleri kendi kurduğu lokantaya aktarmaya çalışmıştır. Ailesinde lokantacılığa ilk merak salan kişi olan Tornacı, tek başına başladığı yorucu lokantacılık hayatında sürekli çalışmayı yeğlemiş ve mesleğe başlama serüvenini şu sözlerle dile getirmiştir: "Biz memur çocuğuyuz, mecburen bu mesleğe düştük. O zamanlar çaydan gelir yoktu, o yüzden lokantacı olalım dedik." Tornacı, lokantanın adını Huzur koymasının sebebini güzel bir nedene bağlayarak "huzurlu bir ortam olsun, huzur dağıtalım diye bu adı koyduk" der (KK.5).

Eskiden Huzur Pide adıyla bilinen, başka şubesi olmayan lokanta, ilk önce pide ve kebap yapımına yönelmiş, daha sonraları sulu yemek vermeye başlamıştır. Pek çok sulu yemek çeşidinin bir arada bulunduğu lokantada yöresel lezzetlerden olan lahana sarması, haşlaması, fasulye tavalisi gibi tatlara da yer verilmektedir. Lokantanın en çok tercih edilen yemeği çoğunlukla et dönerdir. Tatlı olarak ise sütlaç, yöredeki pek çok lokantada olduğu gibi Huzur'da da eski zamanlardan beri yerini muhafaza eden önemli bir lezzettir. Tornacı, yemeklerde kullanılan yağın fabrikasyon olduğunu söyleyerek, Trabzon yağı kullanıldığını belirtir ve Rize'de hayvancılığın olmaması, herkesin çaylığının olmasından dolayı dışarıya bağımlı hale geldiklerini ifade eder (KK.5) Lokanta için gerekli et ise Amasya/Suluova'dan alınmaktadır. Tornacı, etin alındığı yerin sabit olması

\footnotetext{
${ }^{21}$ https://www.youtube.com/watch?v=dl6W-879-e4 (Erişim Tarihi: 22.09.2019).
} 
gerektiğini, aksi takdirde yemeklerin tadında ve pişme süresinde farklılık olacağını dile getirir (KK.5).

Rizeli aşçıların tercih edildiği lokanta, günümüzde Ibrahim Tornacı'nın iki oğlundan biri olan Ahmet Tornacı'nın gözetiminde yürütülmektedir, ancak İbrahim Tornacı, ilerleyen yaşına rağmen çok erken saatlerde mekâna gelerek kendi kurduğu ve uzun yıllardır müşterisinden bir şey kaybetmeyen, hatta müşteri sayısı her geçen gün artarak devam eden lokantada kendini göstermektedir. Lokantada Tornacı'nın kendi torunu da çalışmakta, bir aile işletmesi olarak gelecek günlerde de varlığını sürdürmek için dededen toruna bir kültür aktarımı sağlanmaktadır. "Ben yemek yapmayı bilmem, yaptırmasını bilirim" şeklinde yöneticiliğine vurgu yapan lokanta sahibi, aynı zamanda "yemeği gördüm mü kıvamından anlarım, tadı iyi midir? Müşteriye sunulur mu?" diyerek yemeklerin kalitesinin kontrolünü de kendisinin sağladığını göstermiş olur (KK.5).

Lokantacılık sektörünün yoğun olduğu yaz aylarında müşteri sayısında artış olan lokanta, özellikle öğle yemeklerinde birçok insanın tercih ettiği yerler arasındadır. Öğlen saatlerinde yoğun bir kalabalığın gözlendiği, boş yer bulmanın oldukça zor olduğu lokantanın bu kadar tercih edilmesinin temelinde yatan en önemli sebep elbette ki yemeklerin lezzeti ve kalitesidir. Huzur Restaurant, civardaki esnaf ve memurların da başlıca tercihlerinden biridir. Uzun bir lokantacılık tarihi olan Huzur Restaurant, Rize'nin şu anki kültüründe belleklerde yer etmiş en eski lokantalardan biridir.

\section{Liman Lokantası/ 1968}

1968'de kurulan ve Rize/Merkez'de yer alan lokantayla ilgili işletme sahiplerinden İsmail Reyhanoğlu ile görüşme yapılmıştır.

1964 yılında temelleri atılan lokantanın kurucusu Kemal Reyhanoğlu'dur. ilk olarak Merkez Lokantasını açan Kemal Reyhanoğlu, daha sonra orayı ortağına devrederek Liman Lokantasını kurar. Küçük bir işletmeden bugünkü haline gelen, şehrin en işlek caddelerinden Deniz Caddesinde 1968'den bu yana devam eden bu lezzet durağı, şimdi üçüncü kuşak tarafından işletilmektedir. Babaları Ali Rıza Reyhanoğlu'ndan sonra İsmail Reyhanoğlu ve Faysal Reyhanoğlu, bugün lokantanın aktif bir şekilde varlığını koruyarak yaşatılmasını sağlamaktadırlar. Başka şubesi bulunmayan lokantanın ismi Kemal Reyhanoğlu tarafından verilmiştir, yeri de kendisine aittir. Çamlıhemşin kökenli olduklarını söyleyen İsmail Reyhanoğlu, Türkiye'nin neresine gidersen git; en iyi lokantacı, en iyi fırıncının Çamlıhemşin'den çıktığını söyler ve insanların Liman Lokantasını tercih etmesinin tek sebebinin çok kaliteli yemek yapması olduğunu belirterek lokantacılıkta kaliteli olmanın önemine vurgu yapar (KK.2). Ünlü gurme Vedat Milor, Liman Lokantasıyla ilgili yazdığı yazıda "Rize Liman, herhangi bir esnaf lokantası değil. Yemek kalitesi, hijyeni ve servis düzeyiyle çok iyi iş çıkarıyor. 
Günümüzdeki sahtecilik, çakmalık ve gösteriş merakına tutsak olmadan, eskinin etik değerlerini ve mütevazılığını koruyor." der ve lokantadan oldukça övgü dolu sözlerle bahseder (Milor, 2018). Liman Lokantasının en çok tercih edilen yemeği, meşhur kavurmasıdır. Bunun dışında kuru fasulyesi, döneri, lahana sarması, pidesi de en çok tercih edilen yemekleri arasındadır. İzmir köfte, pide, rosto, et soteden sebzeli kebaba, biber dolmasından haşlama ete menü genişlemektedir (Ünsal, 2018: 427). Yemeklerin bakır tepsi ve kazanlarda pişirildiğini de ayrıca belirtmek gerekmektedir. İsmail Reyhanoğlu, lokantanın en meşhur yemeklerinden olan kavurmayla ilgili olarak şöyle demektedir: “Aslında bunun özelliği kahvaltıda yenmesidir. Sosyal medyada popüler olunca bütün güne yaydık kavurmayı. Kavurmanın özelliği çok kaliteli hammadde almamızdır." (KK.2). Rizeliler, kavurmanın esas kahvaltıda güzel olduğunu söylemektedirler. Sabahın erken saatlerinde ayran veya çay eşliğinde kavurma yiyerek güne başlamak yörede yaygın olan bir kültürdür. Özellikle yaz aylarında kavurma, lokantada günde üç kez çıkmakta ve tüketilmektedir. Ünlü gurme Vedat Milor, lokantanın kavurmasını şöyle anlatır: “...Ama asıl dayanılmaz olan kuzu kavurma. Michelin üç yıldızlı lokantalarda bu son yemek olarak verilse, üzerine destan yazılır. Biz bitiremedik ve yanımıza aldık. Ertesi akşam daha bile lezzetli oldu. Bence en azından haftanın bir günü bu özel kavurma, kuzu etiyle yapılmalı." (Milor, 2018).

Reyhanoğlu, kavurmanın özelliğinin kaliteli hammadde kullanılması olduğunu söyleyerek etlerin nereden alındığına dair bilgi verir. Etlerin çoğunlukla Amasya'nın Suluova ilçesinden Erzurum'dan ve Kars'tan geldiğini belirtir. Reyhanoğlu, tereyağını Trabzon'dan, yoğurdu ise marketten hazır tava yoğurdu aldıklarını söyleyerek bu durumun sebebini Rize ilinde hiç üretim olmamasına, Rize'nin tüketim ili olmasına bağlar. Kavurmayı özel yapanın eti dışında aşçıları olduğunu söyleyerek aşçılarının yanlarında yetişmiş, bulaşıkçı olarak girip usta olmuş kişilerden olduğunu ifade eder (KK.2).

Lokantanın sevilen ve Rize'de de oldukça meşhur olan yemeklerinden biri de kuru fasulyedir. Bunun sebebi sorulduğunda alınan cevap: "Derler ki çay Rize'de yapılır ama Erzurum'da içilir; fasulye de Erzurum'da hammadde olur, burada iyi yapılır." şeklindedir. Türkiye'nin 100 kişilik gastronomi heyetinin seçtiği yemekler arasında Liman Lokantasının kuru fasulyesi 33. sırada en iyi kuru fasulyelerden biri içerisinde değerlendirilir, karalahana sarması ise 99. sırada yer almaktadır (İzci, 2018). Sinan Hamamsarılar, "yolu Doğu Karadeniz'e düşen herkesin bir defa da olsa uğraması gereken bu esnaf lokantasının alametifarikası kavurması, kuru fasulyesi, pilav ve sütlacı" diye söyler (Onat, 2018: 8).

Her şeyi dedelerinden öğrenen İsmail Reyhanoğlu ve Faysal Reyhanoğlu dışında babaları da yaşının verdiği yorgunluğa rağmen işin başındadır. İsmail Reyhanoğlu, dedesinin 1940'lı yıllarda gurbete gittiğini, İstanbul'da Kadıköy'de meşhur bir Liman Lokantasında çalıştığını, orada meslek öğrenip aşçı olduğunu, daha sonra da gelip Rize'de lokanta açtığını söyler (KK.2). Onun verdiği bu 
bilgiler sayesinde lokantanın adını nereden aldığını da öğrenmiş oluruz. Ustaçırak ilişkisi şeklinde devam eden lokantacılığın kendilerinden sonra devam etmeyeceğini, bırakacaklarını; çünkü çocukların bu işle ilgili olmadıklarını belirtir. Reyhanoğlu, sözlerine çok çalışmadan başarının olmayacağını ekleyerek başarılı olmalarının sebebini çalışmalarına bağlar (KK.2).

Lokantanın en önemli özelliklerinden biri yemeklerin bol kepçe olmasıdır. Özellikle çorba, normale göre çok daha fazla bir şekilde servis edilir. Bunun sebebi sorulduğunda şöyle bir cevap alınır: “Biz burayı 1968'de açtığımızda bolluk yoktu, kıtlık vardı. Ekmekleri tavana kadar dizerdik böyle, bir tas çorbayla insanlar karnını doyururdu. Şu anda da bolluk var ama geleneği devam ettiriyoruz." (KK.2).

Müşteri profili olarak sanatçısından iş adamına, bakanından memuruna, esnafına kadar her çeşit insanın uğrak yeri olan liman lokantasında değişik tatlar da kendisine yer bulmaktadır. Özellikle turbo isimli tatlı, oldukça ilgi çekmektedir. İsmail Reyhanoğlu, turboyu 55 yıldan beri yaptıklarını söyleyerek sütlaç yapıp üstüne kadayıf koyduklarını, bunun adına da turbo dendiğini belirtir ve "bildiğim kadarıyla turboyu ilk biz yapmışız" der (KK.2). Ayrıca Reyhanoğlu, yörede pilav üstü kadayıf akımı olduğunu söyleyerek "biz çocukken babaannem pilavın, makarnanın üstüne şeker koyardı. Şeker, pilavla güzel gidiyor. Müşteri istemiş vermişiz, popüler olmuş yani." der (KK.2). Liman Lokantasının bu açıdan gerçekten de değişik tatlara kapı araladığı anlaşılmaktadır, yörede bu tarz zıtlık teşkil eden tatların bir arada/tabakta tüketilmesi de yörenin beslenme alışkanlığındaki farklılıkları dikkate sunmaktadır.

\section{Halil Ibrahim Lokantası/1968}

1968'de Halil İbrahim Çelik tarafından kurulan Halil Ibrahim Lokantası, Rize/Merkez/ Bakırcılar Caddesi'nde yer almaktadır. Lokantayla ilgili Hasan Çelik ve Ali Çelik isimli iki kardeșle yapılan görüşmelerden yararlanılarak bilgi verilmiştir.

1968 yılından beri işletilen lokanta, birçok kez yer değiştirmiştir. Halil İbrahim Çelik tarafından kurulan lokantaya ismini veren de aynı kişidir. Babalarının vefatından sonra lokantayı Hasan Çelik ve Ali Çelik isimli iki kardeş işletmeye başlar. Halil ibrahim Çelik, Rize'de o dönem çay gibi gelir getiren bir şey olmadığı için küçük yaşlardan itibaren gurbete çıkmış, Erzurum, Kars gibi şehirlerde çıraklık yapmış, ỉkizdere'de lokanta işleterek mesleği öğrenmiştir. Daha sonra çocuklarını yanına çırak alarak onlara da mesleğin inceliklerini öğretmiştir. Lokanta şimdi iki kardeş tarafından işletilmektedir ve kardeşler gelecekte işi devralacak kimse olmayışından endişe etmektedirler. Günlük 10-15 çeşit sulu yemeğin yer aldığı lokantanın ününü asıl duyuran lezzeti, babadan öğrenerek devraldıkları ayak paça çorbasıdır. Rize'de çok az yerde bulunabilecek paça çorbasının öncülerinden olan lokanta, bunun dışında et haşlamasıyla da ön 
plana çıkmıştır. Lokantanın müşteri profili her düzeyden insanı kapsamaktadır. Özellikle yakınında bulunan esnafların uğrak yeri durumundadır. Lokantanın bir diğer özelliği aynı masaya birbirini tanımayan insanların oturabilmesidir. Bu durumun sebebi, mekânın dar olması dışında aynı masaya oturmanın bereketi artıracağı düşüncesidir. Bu sayede birlik ve beraberlik sağlanmakta, birbirini tanımayan insanlar aynı sofrayı paylaştıkları kişilerle iletişim kurabilmektedir.

Lokantanın işletmecileri olan Hasan Çelik ve Ali Çelik, babalarının lokantacılığa dair verdiği tavsiyeleri de tuttuklarını söylemektedirler. Dürüstlük ve kaliteden ödün vermemek, dikkate aldıkları en önemli tavsiyelerdendir (KK.8, KK.9). Hammaddeyi Rize'den alan lokantanın dikkat çeken bir diğer özelliği ise masalarda eski usulle büyük ekmek selelerinin yer almasıdır. Bu durum, özellikle geçmiş dönemlerde fazla parası olmayanların ekmek ve çorbayla karnını doyurmalarına fırsat vermiştir.

\section{Lale Lokantası/1973}

Rize'nin Çayeli ilçesi, Dokuz Mart Caddesi'nde yer alan ve 1973 yılında kurulan Lale Lokantasıyla ilgili Ali Osman Temurci ve oğlu Ömer Temurci'yle yapılan görüşmelerden yararlanılmıştır.

1973 yılında Ali Osman Temurci ve ortakları tarafından kurulan Lale Lokantası, 200o'lerde tamamen Ali Osman Temurci ve çocuklarının işletimine geçmiştir. Lale Lokantası ilk kurulduğunda 4-5 masalı küçük bir yer iken günümüzde işletme genişletilmiş ve birçok insanın yemek yemesine olanak sağlayan bir yer olmuştur.

Lale Lokantası adı, başta sadece bir süs bitkisi olması dolayısıyla konulmuş olmasına rağmen lalenin ebced hesabındaki karşılığının Allah lafzına denk gelmesi dolayısıyla 2000'li yıllardan bu yana bu durum içselleştirilmiştir ve soranlara bu cevap verilmektedir. Aile geçmişinde dayısı, amcası gibi başka lokantacılar da olan Ali Osman Temurci, lokantacılık hayatına 14-15 yaşlarında Ankara'da dayısının yanında çalışarak başlar. Ali Osman Temurci, lokanta sektöründe İstanbul, Ankara gibi yerlerde tecrübe kazanmış, asıl mesleği garsonluk iken askerden sonra Rize'deki Hüsrev Lokantası'nda aşçılığı da öğrenmiş, daha sonra bu tecrübe ve bilgileri geliştirerek Rize'nin Çayeli ilçesinde kurduğu lokantanın insanların özellikle kuru fasulye için tercih ettikleri bir yer olmasını sağlamıştır.

Ağırlıklı olarak kuru fasulyeye yer verilen ve bununla meşhur olan lokantada eskiden sadece çorba ve kuru fasulye gibi az çeşit varken zamanla menü geliştirilmiş ve yeni tatlar lokantanın menüsüne eklenmiştir. Lokantada pişirilen kuru fasulyenin en önemli özelliği Erzurum'un İspir/ Hınıs ve Gümüşhane'nin Kelkit/ Şiran gibi ilçelerinden temin edilmesidir. Ömer Temurci, bu fasulyenin özelliğinin kabuğunun ince olması ve kolay pişmesi olduğunu 
belirterek tereyağıyla beraber pişmesi, dana etiyle harmanlanması, taş fırında fırınlanıp bakır tencerede pişirilmesi gibi durumların üretimle ilgili mesafe kat etmelerine imkân tanıdığını söyler. Lokantanın tereyağı ihtiyacı ise Vakfıkebir yöresinden temin edilmektedir. Bu durumun sebebini Ömer Temurci şöyle ifade eder: "Eskiden bizim buralardan gelirdi. O zaman her evde 3-4 tane inek vardı. Şu an bizim köyde beş tane inek yok.” (KK.3).

Çayelili işletmeci, müşteri profilinin yüzde yetmişinin yabancı olduğunu, şehir dışından çok turist geldiğini, Arap turist yoğunluğunun da fazlalığını dile getirip bir zamanlar "Türkiye'yi doyuruyoruz" şeklinde bir reklam yapmak istemiș olduğunu da sözlerine ekler (KK.3). Öğlen saatlerinde memurların yoğunlukta gittiği lokantada öğrencilerin fazla olmadığı görülmektedir. İşletme sahibi Ali Osman Temurci, bunun sebebini lokantadaki fiyatların öğrencilere biraz pahalı gelmesine bağlar (KK.17).

Lale Lokantası, babadan oğula geçen bir aile işletmesi olarak usta-çırak ilişkisi içerisinde yıllara meydan okumaya devam etmektedir. Ali Osman Temurci, çocuklarını daha ilkokul çağlarında lokantaya getirip yemeklerini yedirerek 3-4 saat çalıştırmıştır. Lokantayı aktif olarak işleten oğlu Ömer Temurci ise kendi oğlunu okul dışında burada çalıştırmaktadır. Ömer Temurci, babalarının sorumluluk almadan hayatın kazanılmayacağı, sosyal yaşama girmeyen hiç kimsenin başarılı olamayacağını öğrettiğini söyler. Ali Osman Temurci; çocuklarını küçük yaşta lokantada çalıştırma sebebinin meslek öğrenmelerinden ziyade onların toplumla haşır neşir olmaları, konuşup dertlerini anlatabilmelerini istemesi olduğunu belirtir (KK. 17). 74 yaşında hâlen işletmenin başında olan Ali Osman Temurci ve çocuklarının şiarı "israf etmeden yemek üretmek”tir. Rize'de lokantacılıkta marka olmalarını çok çalışmaya ve ailedeki çalışma birliğine bağlayan Ömer Temurci, bunu örneklendirmek için şunu söyler: "Düğün yaptım. Babam diyor ki: “oğlum işlerimiz var biliyorsun”, ertesi gün işe gelmek zorunda kaldım." (KK.3).

Rize'deki diğer birçok lokanta gibi Lale Lokantası'nın da televizyon, internet ve sosyal medyada görünürlüğü mevcuttur. Çeşitli programlarda yöre lokantalarının tanıtımı, haberi yapılmaktadır. Turgay Başyayla ile Lezzet Yolculuğu'nda Lale Lokantasında iyi bir kuru fasulyenin nasıl yapıldığına dair bilgiler verilir ve kuru fasulye yemeği hazırlanır. ${ }^{22}$

\section{Durak Lokantası/1986}

Rize/Merkez Cumhuriyet Caddesi'nde yer alan lokantayla ilgili Durak Lokantası işletmecilerinden Ali Kılıç ve lokantanın kurucu ustalarından Mehmet Kaba'yla görüşme yapılmıştır.

\footnotetext{
${ }^{22}$ https://www.youtube.com/watch?v=SpznOjgtwKc (Erişim Tarihi: 19.02.2020).
} 
1986 yılında kurulan lokanta, Ali Kılıç ve İbrahim Kılıç tarafından 1997'de Hakkı Karaca'dan devralınmıştır. Durak Lokantası, adını kurulduğu zaman belediye otobüsü duraklarının karşııında bulunmasından almıştır. Kurulduğundan bu zamana sulu yemekler ve dönere yer veren lokanta, halkın yöresel yemeklere ilgisinden dolayı menüyü zenginleştirmiştir. Lokantada 15-20 çeşit sulu yemek de çıkmaktadır. Kuru fasulye, çoban kavurma, lahana sarması gibi yemeklerin yer aldığı lokantada, yemeklerin yapımında kullanılan yağ, Rize'nin yayla köylerinden temin edilmekte, bunun yanında fabrikasyon yağlar da kullanılmaktadır. Et temininde ise Erzurum, Erzincan, Kars, Ardahan ve Artvin gibi iller tercih edilmektedir.

Ali Kılıç, kendilerinin lokantacılık geçmişlerinin bulunmadığını, fakat lokantanın geleneği devam ettirecek kişilerin/çocuklarının olduğunu belirtir (KK.6). Lokantaya gelen müşteri profiline bakıldığında ise bunun genel olarak orta yaş ve üzeri kişiler olduğu göze çarpmaktadır. Masalarının eski usul ahşap olması, esnaf çevresinin ve lokantayı eskiden beri bilenlerin özellikle burayı tercih etmesi, lokantanın bu yaş grubuna hitap etme sebebi olarak düşünülebilir. Lokantanın bir diğer özelliği ise Halil ibrahim Lokantası gibi müşterilerin aynı masada yemek yiyebilmeleridir. Kılıç, lokantanın alt katında bir masada dört sandalye varsa, dört farklı müşterinin olabileceğini belirterek burasının insanların yemeğini yiyip gideceği bir yer olduğunu söyler (KK.6) Lokantanın kurucu ustalarından Mehmet Kaba, eskiden ekmeklerin tavana kadar selelere doldurulduğu şeklinde abartılı bir söylemde bulunarak "öyle olurdu ki aynı masada iki üç kişi, baba-oğul yemek yiyip birbirlerini görmezdi. Ekmek azalınca da adam aa baba sen mi buradaydın?" derdi." (KK.7) şeklinde bir söylemde bulunarak geçmiş dönemlerde ekmeğin lokanta kültüründe ne kadar önemli bir yere sahip olduğunu belirtmiş ve aynı zamanda aynı masada yemek yiyen, birbirini tanıyan kişilerin bazen bir paylaşımda bulunmadıkları için birbirlerinden haberdar olmadan kalktıklarıı da ifade etmiş olur. Lokantanın önünden geçenlerin ustaların slogan gibi "Çay ÇAYKUR'dan, yemek bizden sorulur/ lezzet durağımız/ kalite müthiş, lezzet müthiş." şeklinde yükselen seslerini duymaları mümkündür.

\section{Sonuç}

Beslenme yalnız metabolizmanın ihtiyaçlarını yerine getirme olarak düşünülmemelidir. Toplumlar eski dönemlerden bu yana ırk, coğrafya, din, ekonomik yapı gibi birçok etkenle şekillenen yemek kültürüne sahiptirler. Bu kültür zamanla değişim geçirse de genellikle milli unsurlarını muhafaza eder.

Rize ilinin, sahip olduğu coğrafya, iklim şartları, kadının sürekli çalışmak zorunda olması vb. açılardan ev yemekleri konusunda çok zengin olduğu söylenemez. Yörenin yemek kültüründeki bu zayıflık hissedilmiş olmalı ki yerel halk tarafından zaman içerisinde yeni imkânlar aranmış, ev yemekleri etrafında 
gelişen bu kültür 1950’lerden itibaren değişim geçirmeye başlamıştır. iş̧ sahalarının yeterli olmayışı, işsizlik baskısıyla yüz yüze kalan kişilerin gurbete çıkmasını ve lokantacılık öğrenenlerin Rize'ye dönerek bu alanda faaliyet göstermesini sağlamış, dışarda yeme alışkanlığının da gelişmesiyle bu meslek yörede zamanla toplumsal kabul görmüștür.

Lokantacılığın gelişmesiyle yörede erkeklere mahsus kabul edilen dışarda yeme, kadın ve çocuklara da hitap eder olmuş; yemek kültürünün önemli bir parçası olan düğün, nişan, sünnet ve cenaze yemekleri ile kadınların aralarında düzenledikleri günler de lokanta ve restoranların hizmet alanına girmiştir.

Rize'de yaygınlaşmaya başlayan dışarıda yeme alışkanlığının birçok sebebi vardır. Bu sebepler Rizelileri hem geleneksel yemekleri bulabilecekleri hem de güzel vakit geçirecekleri lokanta ve restoranlara yöneltmektedir. Üstelik sadece mekânı değil bazen aynı masayı da paylaşan kişiler sosyalleşme imkânına da sahip olmaktadırlar.

Kültür, toplumsal değer ve kuralları desteklemede ve kişileri eğitmede önemli bir araçtır. Rize'de yemek hizmetleri açısından gelişme gösteren sektörün usta-çırak ilişkisiyle kültürü yeni kuşaklara öğretmesi dikkat çekicidir. Bu açıdan Rize lokantacılığı bir okul görevini üstlenmiştir.

Rize'deki lokantalarda, tencere yemeği denilen sulu yemek çeşitleri oldukça gelişmiştir. Rize lokantaları, yeni yemek sunumları ortaya koymakta orijinal nitelik taşırlar. Yöre insanının karışık yemek/koalisyon ismiyle bir tabak içerisinde dört-beş çeşit yemeği yan yana koydurarak yemesi civarda oldukça yaygındır. Bunun dışında lokantalarda turbo, pilav üstü kadayıf gibi ilginç tatların da bir arada tüketildiği görülmektedir. Lokantalar, Türkiye'de yaygın bilinen yemeklerle beraber yöresel tatları da yaşatmaktadırlar. Birçok lokantanın ve özellikle restoran adıyla hizmet verenlerin menü kartında muhlama, lahana sarması, turşu tavalisi gibi yöresel lezzetlere yer vermesi, yalnız yöre insanını değil dışarıdan gelen turistleri de cezbetmektedir. Bazıları ise Türkiye'nin her yerinde pişirilmesine rağmen kuru fasulye yemeğini yöreye mal etmekte önemli başarı sağlamıştır. Böylece yöresel veya yöreselleştirilmiş bir yemek kültürüne ve geleneksel tefrişata hatta bazen mimariye sahip olan lokanta ve restoranlar yerliyabancı misafirlerine bu değerleri/kültürü yansıtma ve yaşatmayı seçmişler ve kültürel belleğin aktarımında da önemli rol üstlenmişlerdir.

Sonuç olarak Rize'de dışarda yeme alışkanlığının ortaya çıkmasıyla gelişme gösteren lokanta/restoran işletmeciliğinin yalnız eski-yeni yemek kültürünü değil, yörenin diğer kültürel unsurlarını yaşatmak, genç kuşaklara veya dışardan gelenlere aktarmak, yeni temsilciler yetiştirmek gibi roller üstlendiği, aynı mekânı paylaşan kişileri sosyalleştirdiği tespit edilmiştir. Bunlar da lokantacılıkta bir Rizeli kimliği oluşturmaya katkıda bulunmuştur. 


\section{Kaynakça}

Akarçay, E. (2016). Beslencenin Sosyolojisi Orta Sınıf(lar)ın Yeme İçme ve Eğlence Örüntüleri. Ankara: Phoenix Yayınevi.

Akarçay, E.-N. Suğur. (2015). Dışarıda Yemek: Eskişehir'de Yeni Orta Sınıfın FastFood Yeme-İçme Örüntüleri. Sosyoloji Araştırmaları Dergisi. 18 (1). 1-29.

Beardsworth, A.-T. Keil. (2011). Yemek ve Toplum Çalışmasına Bir Davet Yemek Sosyolojisi. (Çev. A. Dede). Ankara: Phoenix Yayınları.

Beşirli, H. (2010). Yemek, Kültür ve Kimlik. Milli Folklor. 22, (87), 159-169.

Bilici, Ü. (2018). Cumhuriyet Dönemi'nde Doğu Karadeniz Bölgesi'nde Yapılan Kamu Harcamaları ve Yatırımlar (1923-1950). (Yayımlanmamış Doktora Tezi). Atatürk Üniversitesi, Atatürk İlkeleri ve İnkılâp Tarihi Enstitüsü, Erzurum.

Biryol, U. (2015). Gurbet Pastası Hemşinliler, Göç ve Pastacılık. İstanbul: İletişim Yayınları.

Bugge, A. B.- R. Lavik, (2010). Eating Out: A Multifaceted Activity In Contemporary Norway. Food, Culture \& Society. Vol. 13: 2.

Çobanoğlu, Ö. (2012). Halkbilimi Kuramları ve Araştırma Yöntemleri Tarihine Giriş. (6. Baskı). Ankara: Akçağ Yayınları.

Duman, M. (2005). Çay Kitabı. İstanbul: Kitabevi.

Ekici, M. (2007). Halk Bilgisi (Folklor) Derleme ve İnceleme Yöntemleri. (2. Baskı). Ankara: Geleneksel Yayıncilık.

Erkara, O. (2010). 100 Tarihi Lokanta. İstanbul: Cinius Yayınları.

Gökyıldız, S. (2009). İstanbul'un Esnaf Lokantaları. İstanbul: İstanbul Ticaret Odası.

Gürsoy, D. (2013). Tarihin Süzgecinde Mutfak Kültürümüz. (3. Baskı). İstanbul: Oğlak Yayıncılık.

İzci, ì. "Gurmeler, Akademisyenler, Yemek Yazarları, Şefler ve Türkiye'nin En Lezzetli 100 Yemeği.", Hürriyet Pazar, 21 Ocak 2018.

Kunduz, C. Ö.- E. Yirmibeşoğlu. (2019). Hesap Lütfen Dışarıda Yemenin Leziz Hikâyesi. İstanbul: Mundi Kitap.

Malinowski, B. (1992). Bilimsel Bir Kültür Teorisi. (Çev. Saadet Özkal). İstanbul: Kabalcı Yayınevi.

Milor, V. (2014). İstanbul 100 Lokanta. Ankara: NTV Yayınları.

Onaran, B. (2016). Mutfaktarih Yemeğin Politik Serüvenleri. İstanbul: İletişim Yayınları.

Onat, S. "Gördüğünüzde Frene Basacağınız 10 Restoran", Hürriyet Seyahat, 19 Ağustos 2018.

Ritzer, G. (2017). Toplumun McDonaldlaştırılması Çağdaş Toplum Yaşamının Değişen Karakteri Üzerine Bir İnceleme. (5. Baskı). (Çev. A. E. Pilgir). İstanbul: Ayrıntı Yayınları.

Sauner, M. H. (2008). "Kalbe Giden Yol Mideden Geçer” Günümüz Türkiyesi'nin Beslenme Alışkanlıkları. A. Bilgin-Ö. Samancı (Ed.), Türk Mutfağı içinde. (s.261-279). Ankara: Kültür ve Turizm Bakanlığı Yayınları.

Sazkaya, D. A. (2015). Farzet Ki Dönemedim-Kaçkarlar'a Sığmayan Hayatlar-. (5. Baskı). İstanbul: Metamorfoz Yayıncılık. 
Şemseddin Sami. (2004). Kâmûs-ı Türkî. (13. Baskı). İstanbul: Çağrı Yayınları.

Türk Dil Kurumu. (2011). Türkçe Sözlük. (11. bs.). Ankara: Türk Dil Kurumu Yayınları.

Ünsal, A. (1996). Benim Lokantalarım Göz ve Damak Anıları Yüz Yetmiş Adres. (2. Baskı). İstanbul: Yapı Kredi Yayınları.

Ünsal, A. (2018). Benim Lokantalarım İstanbul'dan Anadolu'ya Göz ve Damak Anıları 309 Adres. (6. Baskı). İstanbul: Yapı Kredi Yayınları.

Vedat Milor, “Rize'de Sığınılacak En İyi Liman.” Hürriyet, 19 Mayıs 2018. https://www.hurriyet.com.tr/yazarlar/vedat-milor/rizede-siginilacak-en-iyiliman-40840945 (Erişim Tarihi: 15. 02. 2020).

https://www.hurriyet.com.tr/lezizz/galeri-gunlerde-ikram-ediliyordu-artik-

restoranlara-da-tasindi-41371051/2 (Erişim Tarihi: 20.04.2020).

https://www.comlek.com.tr/hizmetler/is-toplantisi-yemek-organizasyonu

http://rizetso.org.tr/wp-content/uploads/2020/01/17-meslek-grubu.pdf (Erişim

Tarihi: 22.02.2020).

https://www.youtube.com/watch?v=SpznOjgtwKc (Erişim Tarihi: 19.02.2020).

https://www.youtube.com/watch?v=DsdVYHxRSps (Erişim Tarihi: 20.02.2020).

https://www.youtube.com/watch?v=jtIOqpjBvYY (Erişim Tarihi: 20.02.2020).

https://www.youtube.com/watch?v=tYdYoc7EQeo (Erişim Tarihi: 20.02.2020). https://www.youtube.com/watch?v=dl6W-879-e4 (Erişim Tarihi: 22.09.2019).

\section{Kaynak Kișiler}

\begin{tabular}{|c|c|c|c|c|c|c|}
\hline 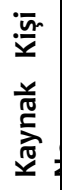 & 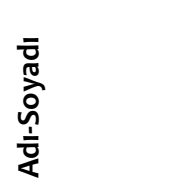 & 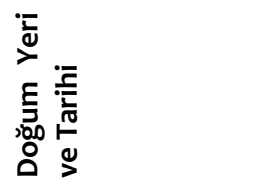 & 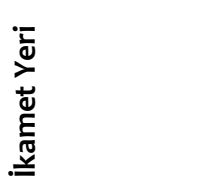 & $\frac{\bar{s}}{\frac{0}{y}}$ & 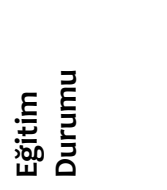 & 峁 \\
\hline 1. & $\begin{array}{l}\text { Orhan Naci } \\
\text { Ak }\end{array}$ & $\begin{array}{l}1937 / \\
\text { Rize/Pazarköy }\end{array}$ & $\begin{array}{l}\text { Rize/ Taşlıdere } \\
\text { Mah. }\end{array}$ & Emekli & Üniversite & 20.11 .2018 \\
\hline 2. & $\begin{array}{l}\text { İsmail } \\
\text { Reyhanoğlu }\end{array}$ & 1975/Rize/ Merkez & Rize/ Merkez & $\begin{array}{l}\text { Lokantacı } \\
\text { /Esnaf }\end{array}$ & $\begin{array}{l}\text { Yüksekokul } \\
\text { Mezunu }\end{array}$ & 31.07 .2019 \\
\hline 3. & $\begin{array}{l}\text { Ömer } \\
\text { Temurci }\end{array}$ & $\begin{array}{l}\text { 1977/Çayeli/ Senoz } \\
\text { Vadisi }\end{array}$ & Çayeli/ Merkez & Lokantacı & $\begin{array}{l}\text { Lise } \\
\text { Mezunu }\end{array}$ & 05.08 .2019 \\
\hline 4. & $\begin{array}{l}\text { Selahattin } \\
\text { Hüsrev }\end{array}$ & $\begin{array}{l}\text { 1973/Çayeli/ } \\
\text { Çilingir Köyü }\end{array}$ & Çayeli/ Merkez & Lokantacı & $\begin{array}{l}\text { İlkokul } \\
\text { Mezunu }\end{array}$ & 18.09 .2019 \\
\hline 5 . & $\begin{array}{l}\text { Ibrahim } \\
\text { Tornacl }\end{array}$ & 1937/Rize/ Merkez & $\begin{array}{l}\text { Rize/ Merkez/ } \\
\text { Ekmekçiler } \\
\text { Mahallesi }\end{array}$ & $\begin{array}{l}\text { Emekli/ } \\
\text { Lokantacı }\end{array}$ & $\begin{array}{l}\text { İlkokul } \\
\text { Mezunu }\end{array}$ & 04.09 .2019 \\
\hline 6. & Ali Kılıç & $\begin{array}{l}\text { 1975/Güneysu/ } \\
\text { Yeni Camii } \\
\text { Mahallesi }\end{array}$ & Rize/ Merkez & Lokantacı & $\begin{array}{l}\text { Lise } \\
\text { Mezunu }\end{array}$ & 04.09 .2019 \\
\hline 7. & $\begin{array}{l}\text { Mehmet } \\
\text { Kaba }\end{array}$ & $\begin{array}{l}\text { 1958/Güneysu/ } \\
\text { Ballıdere Köyü }\end{array}$ & Rize/ Merkez & Aşçı & $\begin{array}{l}\text { ilkokul } \\
\text { Mezunu }\end{array}$ & 04.09 .2019 \\
\hline 8. & Ali Çelik & $\begin{array}{l}\text { 1967/Güneysu/ } \\
\text { Ballıdere Köyü }\end{array}$ & $\begin{array}{l}\text { Rize/ } \\
\text { Merkez/Kale }\end{array}$ & Lokantacı & $\begin{array}{l}\text { İlkokul } \\
\text { Mezunu }\end{array}$ & 04.09 .2019 \\
\hline
\end{tabular}


Ihsan SAFi, Gülhan ATNUR, Damlanur KÜÇÜKYILDIZ

\begin{tabular}{|c|c|c|c|c|c|c|}
\hline & & & Mahallesi & & & \\
\hline 9. & Hasan Çelik & $\begin{array}{l}\text { 1960/Güneysu/Ball } \\
\text { Idere Köyü }\end{array}$ & $\begin{array}{l}\text { Rize/ } \\
\text { Merkez/Kale } \\
\text { Mahallesi } \\
\end{array}$ & Lokantacı & $\begin{array}{l}\text { İlkokul } \\
\text { Mezunu }\end{array}$ & 04.09 .2019 \\
\hline 10. & Hızır Dil & 1959/Rize/ Merkez & Rize/ Merkez & $\begin{array}{l}\text { Emekli/ } \\
\text { Lokantacı }\end{array}$ & $\begin{array}{l}\text { Lise } \\
\text { Mezunu }\end{array}$ & 11.09 .2019 \\
\hline 11. & Necibe Oflu & 1964/Rize/ Merkez & Rize/ Merkez & $\begin{array}{l}\text { Emekli } \\
\text { Memur }\end{array}$ & $\begin{array}{l}\text { Lise } \\
\text { Mezunu }\end{array}$ & 27.06 .2019 \\
\hline 12. & $\begin{array}{l}\text { Hızır } \\
\text { Özdemir }\end{array}$ & $\begin{array}{l}\text { 1949/ikizdere/ } \\
\text { Çifteköprü Köyü }\end{array}$ & Rize/ Merkez & $\begin{array}{l}\text { Emekli } \\
\text { Fırıncı ve } \\
\text { Lokantacı }\end{array}$ & $\begin{array}{l}\text { İlkokul } \\
\text { Mezunu }\end{array}$ & 25.09 .2019 \\
\hline 13. & $\begin{array}{l}\text { Aysun } \\
\text { Bostan }\end{array}$ & $\begin{array}{l}\text { 1977/Rize/ } \\
\text { Merkez/ } \\
\text { Pehlivantaşı Mah. }\end{array}$ & $\begin{array}{l}\text { Rize Merkez/ } \\
\text { Tophane Mah. }\end{array}$ & Pideci & $\begin{array}{l}\text { İlkokul } \\
\text { Mezunu }\end{array}$ & 25.09 .2019 \\
\hline 14. & $\begin{array}{l}\text { Süleyman } \\
\text { Dil }\end{array}$ & 1957/Rize/ Merkez & Rize/ Merkez & Emekli & $\begin{array}{l}\text { ilkokul } \\
\text { Mezunu }\end{array}$ & 11.09 .2019 \\
\hline 15. & $\begin{array}{l}\text { Mustafa } \\
\text { Bakır }\end{array}$ & $\begin{array}{l}\text { 1970/Rize/ } \\
\text { Merkez/ Çaycılar } \\
\text { Köyü }\end{array}$ & Rize/ Merkez & Sütlaçcı & $\begin{array}{l}\text { İlkokul } \\
\text { Mezunu }\end{array}$ & 12.09 .2019 \\
\hline 16. & $\begin{array}{l}\text { Osman } \\
\text { Akgül }\end{array}$ & $\begin{array}{l}\text { 1979/Rize/ } \\
\text { Merkez/ } \\
\text { Pehlivantaşı Mah. }\end{array}$ & $\begin{array}{l}\text { Rize/ } \\
\text { Merkez/ } \\
\text { Pehlivantaşı } \\
\text { Mah. }\end{array}$ & $\begin{array}{l}\text { Pideci/ } \\
\text { Lokantacı }\end{array}$ & $\begin{array}{l}\text { İlkokul } \\
\text { Mezunu }\end{array}$ & 15.12 .2019 \\
\hline 17. & $\begin{array}{l}\text { Ali Osman } \\
\text { Temurci }\end{array}$ & $\begin{array}{l}\text { 1946/Rize/ } \\
\text { Çayeli/ } \\
\text { Uzundere Köyü }\end{array}$ & $\begin{array}{l}\text { Rize/ } \\
\text { Çayeli/ } \\
\text { Büyük Taşhane } \\
\text { Mahallesi } \\
\end{array}$ & Lokantacı & $\begin{array}{l}\text { İlkokul } \\
\text { Mezunu }\end{array}$ & 05.08 .2019 \\
\hline
\end{tabular}

